Board of Governors of the Federal Reserve System

International Finance Discussion Papers

Number 1297

August 2020

\title{
Optimal Taxation with Endogenous Default under Incomplete Markets
}

\author{
Demian Pouzo and Ignacio Presno
}

Please cite this paper as:
Pouzo, Demian and Ignacio Presno (2020). "Optimal Taxation with Endoge-
nous Default under Incomplete Markets," International Finance Discussion Pa-
pers 1297. Washington: Board of Governors of the Federal Reserve System,
https://doi.org/10.17016/IFDP.2020.1297.

NOTE: International Finance Discussion Papers (IFDPs) are preliminary materials circulated to stimulate discussion and critical comment. The analysis and conclusions set forth are those of the authors and do not indicate concurrence by other members of the research staff or the Board of Governors. References in publications to the International Finance Discussion Papers Series (other than acknowledgement) should be cleared with the author(s) to protect the tentative character of these papers. Recent IFDPs are available on the Web at www.federalreserve.gov/pubs/ifdp/. This paper can be downloaded without charge from the Social Science Research Network electronic library at www.ssrn.com. 


\title{
Optimal Taxation with Endogenous Default under Incomplete Markets
}

\author{
Demian Pouzo and Ignacio Presno *
}

July 27,2020

\begin{abstract}
How are the optimal tax and debt policies affected if the government has the option to default on its debt? We address this question from a normative perspective in an economy with noncontingent government debt, domestic default and labor taxes. On one hand, default prevents the government from incurring future tax distortions that would come along with the service of the debt. On the other hand, default risk gives rise to endogenous credit limits that hinder the government's ability to smooth taxes. We characterize the fiscal policy and show how the option to default alters the near-unit root component of taxes in the economy with risk-free borrowing. When we allow the government to default and calibrate the model to Spain, fiscal policies are more volatile, borrowing costs are higher, indebtness and welfare are both lower than in two alternatives economies, one with only risk-free debt available and the other with government's commitment to the default strategy.
\end{abstract}

Keywords: Optimal Taxation, Government Debt, Incomplete Markets, Default.

JEL: H3, H21, H63, D52, C60.

*Pouzo: UC Berkeley, Dept. of Economics, 530-1 Evans \# 3880, Berkeley CA 94720, Email: dpouzo@econ.berkeley.edu; Presno: Board of Governors of the Federal Reserve System, Constitution Ave and 20th Street NW, Washington, DC 20551. Email: ignacio.presno@frb.gov. We are deeply indebted to Xiaohong Chen, Ricardo Lagos and Tom Sargent for their thoughtful advice and insightful discussions. We are also grateful to Arpad Abraham, Mark Aguiar, David Ahn, Andy Atkeson, Marco Basetto, Hal Cole, Nils Goernemann, Jonathan Halket, Greg Kaplan, Gaston Navarro, Juanpa Nicolini, Anna Orlik, Juan Passadore, Nicola Pavoni, Andres Rodriguez-Clare, Ana Maria Santacreu, Ennio Stacchetti, and especially to Ignacio Esponda and Constantino Hevia. We thank for comments and suggestions to seminar participants at Berkeley, CEF 2013, CEMLA, Central Bank of Chile, CREI-UPF, Federal Reserve Board of Governors, FRB of Chicago, Cleveland, Philadelphia and NY, IMF, LACEA-LAMES 2014, LBS, NYU, North American Summer Meeting 2014, Rochester, SED 2013, U of Chicago, UC Davis, UCL, UG, UIUC and UPenn. We are grateful to Nan Lu and Sandra Spirovska for excellent research assistance. Disclaimer: The views expressed in this paper are solely the responsibility of the authors and should not be interpreted as reflecting the views of the Board of Governors of the Federal Reserve System or any other person associated with the Federal Reserve System. 


\section{Introduction}

As originally indicated by Barro [1979], tax smoothing motives play a fundamental role in the design of optimal fiscal policies. The possibility to smooth taxes, however, relies significantly on the market structure for government debt. Relative to the seminal results by Lucas and Stokey [1983] for complete markets economies, Aiyagari et al. [2002] (henceforth, AMSS) shows that taxes typically display higher variability and lower serial correlation under incomplete markets with sufficiently stringent debt and asset limits. In this latter economy, the government is assumed to have access to one-period risk-free bonds. But how are optimal tax and debt policies affected if the government can default on its debt, as we have observed several times throughout history? In this paper we answer this question. Our calibration shows how the presence of default risk and the actual default contingency gives rise to endogenous credit limits that can hinder the government's ability to smooth shocks using debt, resulting in higher tax volatility than in the benchmark incomplete market framework.

We analyze the dynamic taxation problem of a benevolent government with access to distortionary labor taxes and non-state-contingent debt in a closed economy. We assume, however, that the government cannot commit to pay back the debt. ${ }^{1}$ In case the government defaults, it suffers direct costs a direct utility penalty and is excluded from financial markets for a random number of periods.

The government has three policy instruments: (1) distortionary taxes, (2) government debt, and (3) default/repayment decisions. In order to finance the stochastic process of expenditures, the government faces a trade-off between levying distortionary taxes and not defaulting, or issuing debt and thereby increasing the exposure to default risk. Defaulting introduces some degree of state contingency on the payoff of the debt since the financial instrument available to the government becomes an option, rather than a non-state-contingent bond. In equilibrium, the government may optimally decide not to honor its debt contracts — even though the bondholders are the households whose welfare it cares about — because default would prevent the government from incurring in the future tax distortions that would come along with the service of the debt. We believe this is a novel motive to default on government debt which, to our knowledge, had not been explored before in the literature.

\footnotetext{
${ }^{1}$ While in our model we allow only for outright default on government bonds, governments in practice could liquidate the real value of the debt and repayments through inflation risk, which could be viewed as a form of partial default. In several economies, however, this second option may not available, either because the country has surrendered the control over its monetary policy (for example, as in the eurozone, Ecuador, and Panama), or a significant portion of the government debt is either foreign-currency denominated, or local-currency denominated but indexed to the CPI or a similar index. We see our environment particularly appropriate for this class of economies.
} 
The option to default, however, does not come free of charge: in equilibrium households anticipate the possibility of default, demanding a compensation for it embedded in the pricing of the bond; this originates a "Laffer curve" type of pattern for the bond proceedings, thereby implying endogenous credit limits. Two key features stand out in our calibration. First, our calibrated model generates "debt intolerance" endogenously, in contrast with AMSS wherein credit limits are exogenous. Second, in our framework, these credit limits together with higher borrowing costs prevent the government from perfectly spreading the tax burden over time as in the risk-free debt economy.

Our theoretical model is motivated by some observations of tax and debt dynamics along with episodes of domestic defaults throughout the history for a number of economies. To name a few: (1) the government policies and fiscal accounts for France in the 100 years preceding the French Revolution of 1789, wherein France defaulted recurrently and no tax-smoothing features stand out from its debt and tax dynamics; see Sargent and Velde [1995]. ${ }^{2}$ (2) The debt restructuring plan proposed by Secretary of the Treasury Alexander Hamilton for the U.S. economy in 1790 and the policy debates around it. ${ }^{3}$ (3) Finally, several emerging economies, where default is a recurrent event, taxes are more volatile, borrowing costs are sizable, and indebtedness levels are significantly lower than for developed economies. ${ }^{4}$

In a benchmark case, with i.i.d. government expenditure, we characterize analytically the determinants of the optimal default decision and its effects on the optimal taxes, debt and allocations. In particular, we first show that default is more likely when the government expenditure or debt is higher. Second, we prove that the law of motion of the optimal government tax policy departs from the standard martingale-type behavior found in the standard incomplete market framework. Barro [1979] conjectured that optimal debt and taxes should exhibit a random walk behavior. This result was re-affirmed by AMSS in a general equilibrium setup under some re-

\footnotetext{
${ }^{2}$ In contrast, time-series for Great Britain debt broadly resemble Barro's random walk behavior. Great Britain honored all its debt contracts through this period.

${ }^{3}$ As Hall and Sargent [2014] states, through renegotiating the U.S. debt with no discrimination scheme across creditors, Hamilton was hoping to improve the federal government access to credit markets, which in turn would eventually allow for lower borrowing costs to finance temporary increases in government spending and thereby smooth out taxes. Few years later, in 1807, in his report to Congress, Secretary of Treasury Albert Gallatin was advocating for a fiscal policy largely in accord with Barro's tax smoothing idea.

${ }^{4}$ Several domestic defaults for emerging economies were also external. In any case, empirical evidence seems to suggest that government default has a significant direct impact on domestic residents, either because a considerable portion of the foreign debt is in the hands of local investors, or because the government also defaults on domestic debt. For example, for Argentina's default in 2001, about 60 percent of the defaulted debt is estimated to have been in the hands of Argentinean residents; local pension funds alone held almost 20 percent of the total defaulted debt. For Russia's default in 1998 about 60 percent of the debt was held by residents. For Ukraine's default in 1997-98, residents - Ukrainian banks and the National Bank of Ukraine (NBU) among others — held almost 50 percent of the outstanding stock of T-bills. See Sturzenegger and Zettelmeyer [2006].
} 
strictions on asset limits. In our paper we show how this result is altered once default risk is incorporated. More specifically, the law of motion of the optimal government tax policy will be affected, on the one hand, by the benefit from having more state-contingency on the payoff of the bond, but, on the other hand, by the cost of having the option to default (manifested in higher borrowing costs and limited borrowing capacity).

Finally, we conduct a series of numerical exercises to assess the quantitative performance of our model along the aforementioned dimensions. We also consider several alternative economies of interest to assess the relevance of different modelling assumptions on driving the main results. We find that, relative to our baseline economy, letting the government to commit to default strategies eliminates most of the default risk, and induces significantly higher indebtness, resulting in more tax smoothing and higher welfare. Also, the tight credit limits that emerge endogenously with default risk explain a large fraction of the tax volatility, but a non-negligible share is due to the occasionally elevated borrowing costs.

Related Literature. A growing literature has emerged from the seminal work of Barro [1979] highlighting the role of tax-smoothing motives in the design of optimal fiscal and debt policy. In a partial equilibrium deterministic framework, Barro [1979] assumes that the government needs to finance an exogenous sequence of public spending either by levying distortionary taxes or issuing non-state-contingent debt. Barro shows that the government wants to smooth tax distortions across periods by recurring to debt issuance to finance temporary increases in public spending. In a stochastic environment, the model predicts a random walk response of debt and taxes to public spending.

Lucas and Stokey [1983] shows that this result does not survive in an environment with complete markets. In particular, in a general equilibrium setup where a Ramsey planner disposes of distortionary labor taxes and a complete set of Arrow-Debreu securities, Lucas and Stokey [1983] proves that optimal taxes (and debt) do not follow a random walk process but roughly inherit the stochastic properties from the government spending dynamics.

By extending Lucas and Stokey [1983] framework to incomplete markets, AMSS revitalizes Barro [1979] and show that the Ramsey plan prescribes a near-random walk component into debt and taxes under certain conditions for asset/debt limits. Our model builds on AMSS by adding the option for the government to default on its debt, thus endogenizing the ad hoc government credit limits imposed in AMSS, as well as the return on government bonds.

Farhi [2010] extends AMSS by introducing capital accumulation and letting the government to levy capital taxes in addition to labor ones. Other studies that build on the setting of AMSS include Shin [2006] and Bhandari et al. [2017]; we see them as complementary to ours. ${ }^{5}$

\footnotetext{
${ }^{5}$ Angeletos [2002] and Buera and Nicolini [2004] analyze the optimal maturity structure of government debt and show how non-contingent bonds of different maturities can be used to implement the allocations with state-
} 
Our work also contributes to the literature on quantitative default models. We model the strategic default decision of the government as in Arellano [2008] and Aguiar and Gopinath [2006], who first adapted the theoretical framework of Eaton and Gersovitz [1981] to study sovereign default risk and its interaction with the business cycles in emerging economies. From this strand of literature, our paper is closely related to Doda [2007] and Cuadra et al. [2010]. Both papers analyze the procyclicality of fiscal policy in developing countries by solving an optimal taxation problem of a government with distortionary labor taxes and incomplete financial markets. ${ }^{6}$ Their models, however, differ from ours along some important dimensions. First, they consider a small open economy with foreign lenders, while we assume a closed economy. ${ }^{7}$ In our economy, bondholders are the domestic households whose welfare our benevolent government wants to maximize, so tax-smoothing concerns are the dominant determinant in the decision to default or not. Second, we address a different class of question. Instead of exploring fiscal regularities in emerging economies, our work is rather centered on the normative analysis of optimal taxation in the context of government default and provides an analytical characterization of optimal fiscal and debt policies.

Roadmap. The paper is organized as follows. Section 2 introduces the model. Section 3 presents the competitive equilibrium. Section 4 presents the government's problem. Section 5 derives analytical results. Section 6 contains some numerical exercises. Section 7 briefly concludes. All proofs are gathered in the appendices.

\section{The Economy}

In this section we describe the stochastic structure of the model, the timing and policies of the government and present the household's problem.

\subsection{The Setting}

Let time be indexed as $t=0,1, \ldots$ Let $g_{t} \in \mathbb{G} \subset\left[g_{\min }, g_{\max }\right]$ be the government expenditure at time $t$. In order to avoid technical difficulties, we assume cardinal of $\mathbb{G}$ is finite. Also, let $\varsigma_{t}$ be a random variable that dictates if the government regains access to financial markets after contingent debt.

${ }^{6}$ Aguiar et al. [2009] also allow for default in a small open economy with capital where households do not have access to neither financial markets nor capital and provide labor inelastically. The authors' main focus is on capital taxation and the debt "overhang" effect.

${ }^{7}$ From our viewpoint, little attention has been put on quantitative models with domestic default. A notable exception is D'Erasmo and Mendoza [2018], where, in an economy with wealth inequality across domestic agents, redistributional motives influence the incentives to default. Dovis et al. [2016] studies optimal policies for taxes, transfers, and both domestic and external debt in an open economy with competition between political parties. 
defaulting. This variable $\varsigma_{t}$ takes a value of 1 with probability $\lambda$, in which case reentry to financial markets (if applicable) occurs, and 0 otherwise. For any $t \in\{1, \ldots, \infty\}$, let $\omega_{t} \equiv\left(g_{t}, \varsigma_{t}\right)$ be the vector of exogenous state variables in the economy. Let $\Omega^{t} \equiv(\mathbb{G},\{0,1\})^{t}$ be the space of histories of exogenous shocks up to time $t$; a typical element is $\omega^{t}=\left(\omega_{0}, \omega_{1}, \ldots, \omega_{t}\right)$.

\subsection{The Government Policies and Timing}

In this economy, the government finances exogenous government expenditures by levying labor distortionary taxes and trading one-period discount bonds with domestic households. The government, however, cannot commit to repay and may default on the bonds at any point in time. Upon default, all outstanding liabilities are erased; no debt restructuring mechanism is assumed.

Let $\mathbb{B} \subseteq \mathbb{R}$ be compact. Let $B_{t+1} \in \mathbb{B}$ be the quantity of bonds issued at time $t$ to be paid at time $t+1$ so that $B_{t+1}>0$ means that the government is borrowing at time $t$ from households. Let $\tau_{t}$ be the linear labor tax. Also, let $d_{t}$ be the default decision, which takes value 1 if the government decides to default, and 0 otherwise. Also, let $\phi_{t}$ be a variable that takes value 0 if at time $t$ the government cannot issue bonds during this period, and value 1 if it can.

The timing for the government is as follows. Every period that it enters with access to financial markets, after observing the current government expenditure, the government has the option to default on the totality of the outstanding debt carried from last period, $B_{t}$.

If the government exercises the option to default at time $t$, it switches to financial autarky. As borrowing is not allowed that period, the government runs a balanced budget, i.e., tax revenues equal government expenditure. At $t+1$, with probability $\lambda$, the government regains access to financial markets starting over with zero outstanding liabilities. Otherwise, it remains in financial autarky for an additional period.

If instead the government decides not to default, it levies distortionary labor taxes, and allocates discount bonds to the households to cover the expenses $g_{t}$ and pay back the debt carried from last period. Next period, it has again the option to default for the new quantity of bonds.

Therefore, the implied law of motion for $\phi_{t}$ is

$$
\phi_{t} \equiv \phi_{t-1}\left(1-d_{t}\right)+\left(1-\phi_{t-1}\right) \varsigma_{t}
$$

That means that if at time $t-1$, the government was allowed to borrow, then $\phi_{t}=\left(1-d_{t}\right)$, i.e. the government's ability to issue new bonds in the current period depends on whether it defaulted or not on its outstanding debt. But if it was in financial autarky, then $\phi_{t}=\varsigma_{t}$, reflecting the fact that the government regains access to financial markets exogenously with probability $\lambda$. 
As it will become clear later, default on bonds can be seen as a negative lump-sum transfer to households, but a costly one. Default will turn to be costly for two reasons. First, households anticipate the government default strategies and demand higher returns to buy the bond. Second, default comes along with direct costs for the economy, both in terms of welfare and temporary exclusion from financial markets, as shown later.

We now formalize the probability model. Let $\pi: \Omega \rightarrow \mathfrak{P}(\mathbb{G})$ be the Markov transition probability function for the process of government expenditure. ${ }^{8}$

Assumption 2.1. For any $\left(t, g^{t}\right), \operatorname{Pr}\left(g_{t}=g \mid g^{t-1}\right)=\pi\left(g \mid g_{t-1}\right)$ for any $g \in \mathbb{G}$.

Finally, we use $\Pi$ to denote the probability distribution over $\mathbb{G}^{\infty}$ generated by assumption 2.1, and $\Pi\left(\cdot \mid g^{t}\right)$ to denote the conditional probability over $\mathbb{G}$, given $g^{t}$.

The next definitions formalize the concepts of government policy, allocation, prices of bonds and the government budget constraint. In particular, it formally introduces the fact that taxes, default decisions and debt depend only on histories of past realizations of shocks, and in particular that debt is non-state contingent (i.e., $B_{t+1}$ only depends on the history up to time $t$, $\left.\omega^{t}\right)$.

Definition 2.1. Given $B_{0}$ and a stochastic process $\left(g_{t}\right)_{t=0}^{\infty}$, a feasible allocation is a collection of stochastic processes $\left(c_{t}, n_{t}\right)_{t=0}^{\infty}$ such that for each $t,\left(c_{t}, n_{t}\right)$ are measurable with respect to $\omega^{t}$ and $B_{0}$, and for any $\left(t, \omega^{t}\right)$

$$
c_{t}\left(\omega^{t}\right)+g_{t}\left(\omega^{t}\right)=n_{t}\left(\omega^{t}\right)
$$

Definition 2.2. A price process is an stochastic process $\left(p_{t}\right)_{t=0}^{\infty}$ such that for each $t, p_{t}$ is measurable with respect to $\omega^{t}$ and $B_{0}$. A government policy is a collection of stochastic processes $\boldsymbol{\sigma}=\left(B_{t+1}, \tau_{t}, d_{t}\right)_{t=0}^{\infty}$, such that for each $t\left(B_{t+1}, \tau_{t}, d_{t}\right)$ are measurable with respect to $\omega^{t}$ and $B_{0}$.

Finally, we introduce the government budget constraint.

Definition 2.3. A government policy $\boldsymbol{\sigma}$ is attainable, if for all $\left(t, \omega^{t}\right),{ }^{9}$

$$
g_{t}\left(\omega^{t}\right)+\phi_{t}\left(\omega^{t}\right) B_{t}\left(\omega^{t-1}\right) \leq \tau_{t}\left(\omega^{t}\right) n_{t}\left(\omega^{t}\right)+\phi_{t}\left(\omega^{t}\right) p_{t}\left(\omega^{t}\right) B_{t+1}\left(\omega^{t}\right) .
$$

where $\phi_{t}$ evolves according to 2.1.

Observe that in equation 2.3, if the government is excluded from financial markets after defaulting $\left(\phi_{t}\left(\omega^{t}\right)=0\right)$, its budget constraint boils down to $g_{t} \leq \tau_{t}\left(\omega^{t}\right) n_{t}\left(\omega^{t}\right)$. On the other hand, if the government is allowed to borrow $\left(\phi_{t}\left(\omega^{t}\right)=1\right)$, then it has to pay back its debt $B_{t}$ and can issue new bonds.

\footnotetext{
${ }^{8}$ For a finite set $\mathbb{X}, \mathfrak{P}(\mathbb{X})$ is the space of all probability measures defined over $\mathbb{X}$. Also, for any $A \subseteq \mathbb{X}$, the function $\mathbf{1}_{A}(\cdot)$ takes value 1 over the set $A$ and 0 otherwise.

${ }^{9}$ The inequality in equation 2.3 implies that the government can issue lump-sum transfers to the households. Lump-sum taxes are not permitted.
} 


\subsection{The Household's Problem}

There is a continuum of identical households that are price takers and have time-separable preferences for consumption and labor processes. For simplicity, we endow them with quasilinear preferences. The main results can be extended for more general preferences. Households also make savings decisions by trading government bonds. Formally, we define a household debt process as a stochastic process given by $\left(b_{t+1}\right)_{t=0}^{\infty}$ where $b_{t+1}: \Omega^{t} \rightarrow[\underline{b}, \bar{b}]$ is the household's savings in government bonds at time $t+1$ for any history $\omega^{t} .{ }^{10}$

From the households' point of view (which takes government actions as given) the bond is an asset with a state-dependent payoff. This dependence clearly illustrates that default decisions add certain degree of state contingency to the government debt.

The household's problem consists of choosing consumption, labor and debt processes in order to maximize the expected lifetime utility. That is, given $\left(\omega_{0}, b_{0}\right)$ and $\boldsymbol{\sigma}$,

$$
\sup _{\left(c_{t}, n_{t}, b_{t+1}\right)_{t=0}^{\infty} \in \mathbb{C}\left(g_{0}, s_{0}, b_{0} ; \boldsymbol{\sigma}\right)} E_{\Pi\left(\cdot \mid \omega_{0}\right)}\left[\sum_{t=0}^{\infty} \beta^{t}\left(c_{t}\left(\omega^{t}\right)+H\left(1-n_{t}\left(\omega^{t}\right)\right)-\left(1-\phi_{t}\left(\omega^{t}\right)\right) \psi\left(g_{t}\left(\omega^{t}\right)\right)\right)\right]
$$

where $H$ is the utility from leisure $\left(1-n_{t}\right), \beta \in(0,1)$ is the discount factor, $\psi: \mathbb{G} \rightarrow \mathbb{R}_{+}$ is a utility penalty if the economy is in financial autarky following a default announcement, $E_{\Pi\left(\cdot \mid \omega_{0}\right)}[\cdot]$ is the expectation using the conditional probability $\Pi\left(\cdot \mid \omega_{0}\right)$, and $\mathbb{C}\left(g_{0}, b_{0} ; \boldsymbol{\sigma}\right)$ is the set of household's allocations and debt process that, given government policy $\boldsymbol{\sigma}$, satisfy the households' budget constraint for all $t$ and all $\omega^{t} \in \Omega^{t}$,

$$
c_{t}\left(\omega^{t}\right)+\phi_{t} p_{t}\left(\omega^{t}\right) b_{t+1}\left(\omega^{t}\right)=\left(1-\tau_{t}\left(\omega^{t}\right)\right) n_{t}\left(\omega^{t}\right)+\phi_{t}\left(\omega^{t}\right) b_{t}\left(\omega^{t-1}\right)+T_{t}\left(\omega^{t}\right)
$$

where $T_{t}\left(\omega^{t}\right) \geq 0$ are lump-sum transfers from the government. The budget constraint indicates that after-tax labor income, proceedings from bond holdings and government transfers have to be sufficient to cover consumption and new purchases of government bonds.

From here on, we proceed under the following assumption on the specification of the utility term for leisure.

Assumption 2.2. $H \in \mathbb{C}^{2}([0,1], \mathbb{R})$ with $H^{\prime}(l)>0, H^{\prime}(1)<1, \lim _{l \rightarrow 0} H^{\prime}(l)=\infty, H^{\prime \prime}(l)<0$ and $2 H^{\prime \prime}(l)<H^{\prime \prime \prime}(l)(1-l)$.

This assumption is analogous to assumption in p. 10 in AMSS, and it ensures that $H$ is smooth enough to compute first order conditions. ${ }^{11}$

\footnotetext{
${ }^{10}$ We assume $b_{t+1} \in[\underline{b}, \bar{b}]$ with $[\underline{b}, \bar{b}] \supset \mathbb{B}$ so in equilibrium these restrictions will not be binding.

${ }^{11} \mathbb{C}^{2}(X, Y)$ is the space of twice continuously differentiable functions from $X$ to $Y$.
} 


\section{Competitive Equilibrium}

We now define a competitive equilibrium for a given government policy and derive the equilibrium taxes and prices.

Definition 3.1. Given $\omega_{0}, B_{0}=b_{0}$ and a stochastic process $\left(g_{t}, s_{t}\right)_{t=0}^{\infty}$, a competitive equilibrium is a government policy $\boldsymbol{\sigma}$, an allocation $\left(c_{t}, n_{t}\right)_{t=0}^{\infty}$, a household debt process $\left(b_{t+1}\right)_{t=0}^{\infty}$, and a price process $\left(p_{t}\right)_{t=0}^{\infty}$ such that:

1. Given the government policy and the price process, the allocation and debt process solve the household's problem.

2. The government policy $\boldsymbol{\sigma}$ is attainable.

3. The allocation is feasible.

4. For all $\left(t, \omega^{t}\right), B_{t+1}\left(\omega^{t}\right)=b_{t+1}\left(\omega^{t}\right)$.

\subsection{Equilibrium Prices and Taxes}

In this section we present the expressions for equilibrium taxes and prices of debt. The former quantity is standard (e.g. AMSS and Lucas and Stokey [1983]); the latter quantity, however, incorporates the possibility of default of the government.

From the first order conditions of the optimization problem of the households (assuming an interior solution) the following equations hold for any $\left(t, \omega^{t}\right),{ }^{12}$

$$
H^{\prime}\left(1-n_{t}\left(\omega^{t}\right)\right)=1-\tau_{t}\left(\omega^{t}\right)
$$

and

$$
p_{t}\left(\omega^{t}\right)=\beta E_{\Pi\left(\cdot \mid \omega^{t}\right)}\left[1-d_{t+1}\left(\omega^{t+1}\right)\right]
$$

Equation 3.5 reflects the fact that in equilibrium households anticipate the default strategies of the government and demand higher returns to compensate for the default risk.

\subsection{Characterization of the Competitive Equilibrium}

In this environment, the set of competitive equilibria can be characterized by a sequence of non-linear equations which impose restrictions on $\left(d_{t}, B_{t+1}, n_{t}\right)_{t=0}^{\infty}$ and are derived from the first order conditions of the household, the budget constraint of the government and the feasibility condition.

\footnotetext{
${ }^{12}$ See appendix B for the derivation.
} 
Henceforth, we call $\left(d_{t}, B_{t+1}, n_{t}\right)_{t=0}^{\infty}$ an outcome path of allocations. We say an outcome path is consistent with a competitive equilibrium if the outcome path and $\left(c_{t}, p_{t}, b_{t+1}, \tau_{t}, g_{t}\right)_{t=0}^{\infty}$, derived using the market clearing, feasibility and first order conditions, is a competitive equilibrium. Also, let

$$
\left.Z_{t}\left(\omega^{t}\right) \equiv z\left(n_{t}\left(\omega^{t}\right), g_{t}\left(\omega^{t}\right)\right)=\left(1-H^{\prime}\left(1-n_{t}\left(\omega^{t}\right)\right)\right)\right) n_{t}\left(\omega^{t}\right)-g_{t}\left(\omega^{t}\right)
$$

be the primary surplus (if it is negative, it represents a deficit) at time $t$ given history $\omega^{t} \in \Omega^{t}$.

Proposition 3.1. Given $\omega_{0}$ and $B_{0}=b_{0}$, the outcome path $\left(d_{t}, B_{t+1}, n_{t}\right)_{t=0}^{\infty}$ is consistent with a competitive equilibrium iff for all $\left(t, \omega^{t}\right)$, the following holds:

$$
\begin{aligned}
Z_{t}\left(\omega^{t}\right)+\phi_{t}\left(\omega^{t}\right)\left\{p_{t}\left(\omega^{t}\right) B_{t+1}\left(\omega^{t}\right)-\phi_{t} B_{t}\left(\omega^{t-1}\right)\right\} & \geq 0, \\
B_{t}\left(\omega^{t}\right)=0 \text { if } \phi_{t}\left(\omega^{t}\right) & =0
\end{aligned}
$$

and $c_{t}\left(\omega^{t}\right)=n_{t}\left(\omega^{t}\right)-g_{t}\left(\omega^{t}\right)$ and equations 3.4 and 3.5 hold.

Equation 3.7 summarizes the budget constraint of the government but replacing prices and taxes by the first order conditions, as in the "primal approach" used by Lucas and Stokey [1983] and AMSS.

\section{The Government Problem}

The government is benevolent and maximizes the welfare of the representative household by choosing policies. In this setup, the government cannot commit to taxes nor repaying the debt; in autarky it chooses taxes that balance its budget. The assumption about quasi-linear preferences, however, facilitates the comparison to the optimal taxation literature in the spirit of Lucas and Stokey [1983] and AMSS because whether the government can commit to fiscal policies is irrelevant in that framework since it cannot manipulate the risk-free rate through its tax choices.

\subsection{Recursive Representation of the Government Problem}

In this section we adopt a recursive representation of the government problem. We focus on Markov perfect equilibrium. Therefore, in each period, the governments equilibrium default, borrowing, and tax decisions are assumed to depend only on payoff-relevant state variables.

Every period the government enters with access to financial markets, it evaluates the utility of honoring the debt contract against the utility of repudiating them, and bases on it its default decision. 
Therefore, for any current state $(g, B)$, the value for the government of having the option to default $V^{*}(g, B)$ is given by ${ }^{13}$

$$
V^{*}(g, B)=\max _{d \in\{0,1\}}\left\{(1-d) V_{1}^{*}(g, B)+d V_{0}^{*}(g)\right\}
$$

where the value of repaying $V_{1}^{*}(g, B)$ satisfies the Bellman equation

$$
\begin{gathered}
V_{1}^{*}(g, B)=\max _{\left(n, B^{\prime}\right) \in \Gamma(g, B)}\left\{n-g+H(1-n)+\beta \int_{\mathbb{G}} \max \left\{V_{1}^{*}\left(g^{\prime}, B^{\prime}\right), V_{0}^{*}\left(g^{\prime}\right)\right\} \pi\left(d g^{\prime} \mid g\right)\right\}, \\
\text { with } \quad \Gamma(g, B)=\left\{\left(n, B^{\prime}\right) \in[0,1] \times \mathbb{B}: z(n, g)+\mathcal{P}^{*}\left(g, B^{\prime}\right) B^{\prime}-B \geq 0\right\}, \\
\mathcal{P}^{*}\left(g, B^{\prime}\right)=\beta \int_{\mathbb{G}}\left(1-\mathbf{d}^{*}\left(g^{\prime}, B^{\prime}\right)\right) \pi\left(d g^{\prime} \mid g\right),
\end{gathered}
$$

and the value of defaulting is $V_{0}^{*}(g)$ is given by

$$
V_{0}^{*}(g)=\mathbf{n}_{0}^{*}(g)-g+H\left(1-\mathbf{n}_{0}^{*}(g)\right)-\psi(g)+\beta \int_{\mathbb{G}}\left[\lambda V_{1}^{*}\left(g^{\prime}, 0\right)+(1-\lambda) V_{0}^{*}\left(g^{\prime}\right)\right] \pi\left(d g^{\prime} \mid g\right),
$$

where $\mathbf{n}_{0}^{*}(g)=\arg \max _{n \in[0,1]}\{n-g+H(1-n): z(n, g)=0\}$.

The equilibrium default decision $\mathbf{d}^{*}(g, B)$ embedded in the pricing equation is for all $(g, B)$ given by

$$
\mathbf{d}^{*}(g, B)= \begin{cases}0 & \text { if } V_{1}^{*}(g, B) \geq V_{0}^{*}(g) \\ 1 & \text { if } V_{1}^{*}(g, B)<V_{0}^{*}(g)\end{cases}
$$

Observe that the autarkic optimal labor allocation $\mathbf{n}_{0}^{*}(g)$ given $g$ maximizes current perperiod payoff subject to a balanced budget.

Below we present some particular cases of special interest in order to illustrate the objects in the government problem.

Example 4.1 (non-defaultable debt). Consider an economy with (ad hoc) risk-free debt. The value function $V_{0}^{*}$ is irrelevant and $V_{1}^{*}$ boils down to

$$
V_{1}^{*}(g, B)=\max _{\left(n, B^{\prime}\right) \in \Gamma(g, B)}\left\{n-g+H(1-n)+\beta \int_{\mathbb{G}} V_{1}^{*}\left(g^{\prime}, B^{\prime}\right) \pi_{\mathbb{G}}\left(d g^{\prime} \mid g\right)\right\}
$$

where

$$
\Gamma(g, B)=\left\{\left(n, B^{\prime}\right): z(n, g)+\beta B^{\prime}-B \geq 0\right\} .
$$

This case is precisely the type of model studied in AMSS

\footnotetext{
${ }^{13}$ Given the i.i.d. nature of $\omega$, history $\omega^{t}$ is only relevant to describe the current state of the economy to the extent that it helps determine the credit status $\phi_{t}$ (already indexing the value functions in the recursive problem). Consequently, we do not include it in the state vector $(g, B)$.
} 
The following example is analogous to standard endowment-economy models of sovereign default, but with a "non-standard" per-period utility that reflects the distortive nature of the labor tax.

Example 4.2 (Baseline without utility penalty). Assume $\psi(g)=0$ for every $g \in \mathbb{G}$. In this case, the value of default is given by

$$
V_{0}^{*}(g)=\boldsymbol{n}_{0}^{*}(g)-g+H\left(1-\boldsymbol{n}_{0}^{*}(g)\right)+\beta \int V_{1}^{*}\left(g^{\prime}, 0\right) \pi\left(d g^{\prime} \mid g\right) .
$$

Note that there is no need to keep the debt B as part of the state after a default since none of the defaulted debt is ever repaid, and all the offers of zero repayment are accepted by the government. The value during financial access is given by

$$
V_{1}^{*}(g, B)=\max _{\left(n, B^{\prime}\right) \in \Gamma(g, B)}\left\{n-g+H(1-n)+\beta \int \max \left\{V_{1}^{*}\left(g^{\prime}, B^{\prime}\right), V_{0}^{*}\left(g^{\prime}\right)\right\} \pi\left(d g^{\prime} \mid g\right)\right\},
$$

where $\Gamma(g, B) \equiv\left\{\left(n, B^{\prime}\right): z(n, g)+\beta E_{\pi(\cdot \mid g)}\left[\mathbf{1}_{\left\{g^{\prime}: V_{1}^{*}\left(g^{\prime}, B^{\prime}\right) \geq V_{0}^{*}\left(g^{\prime}\right)\right\}}\left(g^{\prime}\right)\right] B^{\prime}-B \geq 0\right\}$.

Moreover, assuming $H^{\prime}(1)<1$ and $2 H^{\prime \prime}(l)<H^{\prime \prime \prime}(l)(1-l)$, we can view the government problem as directly choosing tax revenues $R$ with a per-period payoff given by $W(R)=n(R)+$ $H(1-n(R))$ where $n(R)$ is the amount of labor needed to collect revenues equal to $R$. Under our assumptions, $W(\cdot)$ is non-increasing and concave function. The Bellman equation of the value of repayment is given by

$$
V_{1}^{*}(g, B)=\max _{\left(R, B^{\prime}\right)}\left\{W(R)-g+\beta \int \max \left\{V_{1}^{*}\left(g^{\prime}, B^{\prime}\right), V_{0}^{*}\left(g^{\prime}\right)\right\} \pi\left(d g^{\prime} \mid g\right)\right\},
$$

subject to $R+\beta E_{\pi(\cdot \mid g)}\left[\mathbf{1}_{\left\{g^{\prime}: V_{1}^{*}\left(g^{\prime}, B^{\prime}\right) \geq V_{0}^{*}\left(g^{\prime}\right)\right\}}\left(g^{\prime}\right)\right] B^{\prime} \geq g+B$, and

$$
V_{0}^{*}(g)=W(g)-g+\beta \int\left[\lambda V_{1}^{*}\left(g^{\prime}, 0\right)+(1-\lambda) V_{0}^{*}\left(g^{\prime}\right)\right] \pi\left(d g^{\prime} \mid g\right) .
$$

This problem is analogous to that studied in Arellano [2008] and Aguiar and Gopinath [2006] among others, where the government chooses how much to "consume", captured by $-R$, given an exogenous process of "income", -g. An important difference, however, is the non-standard per-period payoff which has a satiation point at $R=0$ (i.e., zero distortive taxes). ${ }^{14}$

In the previous example, the expression for the price function, $E_{\pi_{\mathbb{G}}(\cdot \mid g)}\left[\mathbf{1}_{\left\{g^{\prime}: V_{1}^{*}\left(g^{\prime}, \cdot\right) \geq V_{0}^{*}\left(g^{\prime}\right)\right\}}\left(g^{\prime}\right)\right]$, highlights an important difference between our default model and a model with risk-free debt such as AMSS. Since the marginal utility of consumption is always one under quasi-linear preferences, the market stochastic discount factor is equal to $\beta$, and thus in the AMSS model the

\footnotetext{
${ }^{14}$ Another subtle difference with the standard sovereign default literature is that while in our economy government and bondholders share the same preference, in this literature they do not. In particular, the government tends to be more impatient than (foreign) investors, thus bringing about incentives to front-load consumption through borrowing.
} 
government cannot manipulate the return of the discount bond. In our economy, however, the government is still able to manipulate the return of the discount bond by altering its payoff through the decision of default.

\section{$5 \quad$ Analytical Results}

We present analytical results for a benchmark model characterized by i.i.d. government expenditure shocks. The proofs for the results are gathered in appendix D.

Assumption 5.1. For any $g^{\prime} \neq g, \pi(\cdot \mid g)=\pi\left(\cdot \mid g^{\prime}\right)$.

With a slight abuse of notation and to simplify the exposition we use $\pi(\cdot)$ to denote the probability measure of $g$. Finally, to further simplify the technical details, we assume that $\mathbb{B}$ has only finitely many points, unless stated otherwise. ${ }^{15}$ For the rest of the section, assumption 5.1 holds and will not be referenced explicitly.

\subsection{Implications for Equilibrium Prices, Taxes and Default Decisions}

We now study the implications of the above results on equilibrium prices, taxes and default strategies.

The next proposition characterizes the optimal decisions to default as "threshold decisions".

Proposition 5.1. Default decisions. There exists a $\bar{g}: \mathbb{B} \rightarrow \mathbb{G}$ such that $\mathbf{d}^{*}(g, B)=$ $\mathbf{1}_{\{g: g \geq \bar{g}(B)\}}(g)$ and $\bar{g}($.$) non-increasing for all B>0$.

This result extends that in Arellano [2008] to our setting with distortionary taxation. It shows that default is more likely to occur for high levels of debt.

Equilibrium prices and endogenous debt limits. Under assumption 5.1 equilibrium prices do not depend on $g$, i.e., $\mathcal{P}^{*}(\cdot) \equiv \mathcal{P}^{*}(g, \cdot)$ for any $g \in \Omega$.

A key feature of endogenous default models is the existence of endogenous borrowing limits. A necessary condition for this result to hold is that, due to the possibility of default, equilibrium prices $\mathcal{P}^{*}\left(B^{\prime}\right)$ are non-increasing as a function of debt $B^{\prime}$, thus implying a "Laffer-type curve" for the revenues coming from selling bonds. This is the case in our economy by proposition 5.1. Moreover, it takes value zero for sufficiently high $B^{\prime}$. Therefore, there exists an endogenous debt limit, i.e., finite value of $B^{\prime}$ that maximize the debt revenue $\mathcal{P}^{*}\left(B^{\prime}\right) B^{\prime}$.

\footnotetext{
${ }^{15}$ This assumption is made for simplicity. It can be relaxed to allow for general compact subsets, but some of the arguments in the proofs will have to be changed slightly. Also, $\mathbb{B} \equiv\left\{B_{1}, \ldots, B_{|\mathbb{B}|}\right\}$ is only imposed for the government; the households can still choose from convex sets; only in equilibrium we impose $\left\{B_{1}, \ldots, B_{|\mathbb{B}|}\right\}$.
} 
This result is consistent with the evidence of the positive relationship between debt-to-output levels and default risk measures; see section $\mathrm{E}$ in the supplementary material. In addition, the existence of endogenous borrowing limits implies that the ability to roll over high levels of debt is hindered. Since the primary surplus function $z(\cdot, \Omega)$ is concave in $n$, as shown in lemma D.1 of appendix D, labor is more "sensitive" to fluctuations in government expenditure when the indebtedness level is high. This feature is consistent with the stylized fact that on average higher volatility of tax revenue-to-output ratios is observed when debt and default risk are high. We further explore this mechanism in the numerical simulations.

Default risk and the law of motion of equilibrium taxes. In order to analyze the exante effect of default risk on the law of motion of taxes, we strengthen assumption 2.2 by requiring that $H^{\prime \prime}(l)<H^{\prime \prime \prime}(l)(1-l)$. When the government is allowed to borrow, the implementability constraint is given by

$$
B_{t}\left(\omega^{t-1}\right)+g_{t} \leq\left(1-H^{\prime}\left(1-n_{t}\left(\omega^{t}\right)\right)\right) n_{t}\left(\omega^{t}\right)+\mathcal{P}^{*}\left(B_{t+1}\left(\omega^{t}\right)\right) B_{t+1}\left(\omega^{t}\right)
$$

where $\mathcal{P}^{*}\left(\omega_{t}, B_{t+1}\left(\omega^{t}\right)\right) \equiv E_{\pi}\left[1-\mathbf{d}^{*}\left(\omega^{\prime}, B_{t+1}\left(\omega^{t}\right)\right)\right]$. Let $\nu_{t}\left(\omega^{t}\right)$ be the Lagrange multiplier associated to this restriction in the optimization problem of the government, given $\omega^{t} \in \Omega^{t}$. In appendix D.1 we derive the FONC of the government and provide a closed-form expression for $\nu_{t}\left(\omega^{t}\right)$ as a decreasing nonlinear function of $n_{t}\left(\omega^{t}\right)$; see equation D.28. Hence, as noted by AMSS, studying the law of motion of $\nu_{t}$ we can shed light on the law of motion of taxes. ${ }^{16}$

From the FONC of the government it follows (see appendix D.1 for the derivation) ${ }^{17,18}$

$\nu_{t}\left(\omega^{t}\right)\left(1+\frac{d \mathcal{P}^{*}\left(B_{t+1}\left(\omega^{t}\right)\right)}{d B_{t+1}} \frac{B_{t+1}\left(\omega^{t}\right)}{\mathcal{P}^{*}\left(B_{t+1}\left(\omega^{t}\right)\right)}\right)=\int_{\Omega} \nu_{t+1}\left(\omega^{t}, \omega^{\prime}\right) \frac{1\left\{g^{\prime} \leq \bar{g}\left(B_{t+1}\left(\omega^{t}\right)\right)\right\}}{\int_{\Omega} 1\left\{g^{\prime} \leq \bar{g}\left(B_{t+1}\left(\omega^{t}\right)\right)\right\} \pi\left(d \omega^{\prime}\right)} \pi\left(d \omega^{\prime}\right)$.

Equation 5.14 reflects the role of debt for tax-smoothing purposes and the trade-off the government is confronted with. The Lagrange multiplier associated with the implementability condition is constant in Lucas and Stokey [1983] and, thus, trivially a martingale. In AMSS, away from the asset limits, the Lagrange multiplier associated with the implementability condition is a martingale with respect to the probability measure $\pi$; i.e., the government spreads over time the tax burden up to the point that $\nu_{t}$ is equal to $\nu_{t+1}$ in expected terms. Equation 5.14 implies that in our economy this is not the case; the presence of default risk affects the law of motion

\footnotetext{
${ }^{16}$ Under our assumptions, $\tau_{t}$ are decreasing in $n_{t}\left(\omega^{t}\right)$ which, in turn, implies a positive relationship between $\nu_{t}$ and $\tau_{t}$.

${ }^{17}$ This derivation assumes that $\mathbb{B}$ is a convex set and $\pi_{\mathbb{G}}$ has a density with respect to the Lebesgue measure, so as to make sense of differentiation. It also assumes differentiability of $V^{*}$.

${ }^{18}$ The martingale property is also preserved if capital is added to the economy; see Farhi [2010].
} 
of the Lagrange multiplier in two important ways. First, the expectation is computed under the so-called default-adjusted probability measure, given by $\frac{1\left\{\cdot \leq \bar{g}\left(B_{t+1}\left(\omega^{t}\right)\right)\right\}}{\int_{\Omega} 1\left\{g^{\prime} \leq \bar{g}\left(B_{t+1}\left(\omega^{t}\right)\right)\right\} \pi\left(d \omega^{\prime}\right)} \pi(\cdot)$. The default-adjusted probability measure is first-order dominated by $\pi_{\mathbb{G}}$, which reflects the fact that the option to default adds "some" degree of state-contingency to the payoff of the government debt. In particular, it implies that only the states tomorrow in which there is repayment are relevant for the law of motion of $\nu_{t}$. Moreover, to the extent that $\nu_{t}\left(\omega^{t},.\right)$ is increasing, the lefthand side of the equation is lower than the expectation of $\nu_{t+1}$ under $\pi$. Second, $\nu_{t}\left(\omega^{t}\right)$ in the left-hand side is multiplied by $\left(1+\frac{d \mathcal{P}^{*}\left(B_{t+1}\left(\omega^{t}\right)\right)}{d B_{t+1}} \frac{B_{t+1}\left(\omega^{t}\right)}{\mathcal{P}^{*}\left(B_{t+1}\left(\omega^{t}\right)\right)}\right)$, which can be interpreted as the "markup" that the government has to pay for having the option to default. In the presence of default risk the markup is less than one and hence $\nu_{t}$ is higher than the expectation of $\nu_{t+1}$ under the default-adjusted probability measure. This reflects the fact that default risk entails higher borrowing costs and limited debt issuance which prevent the government from smoothing taxes completely, as it would be the case if $\nu_{t}$ were a martingale, like in the risk-free debt economy. ${ }^{19}$

These two forces act in opposite directions, and is not clear which one will prevail when setting taxes. ${ }^{20}$ In order to shed more light on this issue, in section 6 we explore quantitatively this trade-off by studying the impulse responses of $\nu_{t}$.

\section{Quantitative Analysis}

As explained in the previous subsection, endogenous credit limits play a crucial role in driving the volatility of taxes. To better understand how different modeling assumptions shape these credit limits and hence tax dynamics, we consider three alternative economies of interest.

\subsection{Alternative Economies}

The first economy is a standard risk-free bond model with natural debt limits, as in AMSS, but without savings. We label this economy "AMSS"; details can be found in AMSS. ${ }^{21}$ The

\footnotetext{
${ }^{19}$ In a dynamic model with market segmentation for government debt and selective default, Paczos and Shakhnov [2018] find that domestic debt is used to smooth taxes when tax wedge shocks hit the economy, in line with our main findings. While tax distortions are exogenous in their setup, in ours they emerge endogenously as labor taxes distort households' intratemporal consumption-leisure decisions.

${ }^{20}$ In a more general framework, when households are averse to consumption risk, a third force emerges as the government can manipulate not only the price of the defaultable bond but the risk-free rate as well. In that case, the government understands that increasing borrowing would raise households' marginal utility of next-period consumption, which in turn implies lower bond prices or equivalently higher borrowing costs in the current period.

${ }^{21} \mathrm{~A}$ natural question in this context is what characteristics of an economy will prompt it to behave as the AMSS or default model prescribe, in particular when it comes to the propensity or willingness to honor debt contracts. Several reasons have been put forth to explain why some governments always repay while some others do not. Incentives to default may be driven by factors related to political instability and polarization (see for example
} 
second economy features also a risk-free bond but with ad hoc borrowing limits, given by solvency constraints that induce the government to always repay over defaulting and switching to financial autarky. We label this economy "risk-free debt model with solvency constraints", or SC for short. In the third and last economy, the government can trade a defaultable one-period bond, but, in contrast with the baseline economy, has the ability to commit to next-period default decision. This is the "model with commitment to default", or CD for short. We next describe in more detail the two latter economies.

Risk-free debt model with solvency constraints. In this economy the government can issue bonds at a risk-free rate but its quantity is restricted by solvency constraints that guarantee that in the next period the value of honoring the debt contract always exceeds that of repudiating it and walking away for a random number of periods. ${ }^{22}$

In this economy the government's problem given current state $(g, B)$ is

$$
\begin{gathered}
W_{1}^{*}(g, B)=\max _{\left(n, B^{\prime}\right) \in \Gamma(g, B)}\left\{n-g+H(1-n)+\beta \int_{\mathbb{G}} W_{1}^{*}\left(g^{\prime}, B^{\prime}\right) \pi\left(d g^{\prime} \mid g\right)\right\}, \\
\text { with } \quad \Gamma(g, B)=\left\{\left(n, B^{\prime}\right) \in[0,1] \times \mathbb{B}: z(n, g)+\beta B^{\prime}-B \geq 0\right\}, \\
W_{1}^{*}\left(g^{\prime}, B^{\prime}\right) \geq W_{0}^{*}\left(g^{\prime}\right) \text { for all } g^{\prime}
\end{gathered}
$$

where the value of defaulting $W_{0}^{*}\left(g^{\prime}\right)$ is the same as in the baseline model,

$$
W_{0}^{*}(g, B)=\mathbf{n}_{0}^{*}(g)-g+H\left(1-\mathbf{n}_{0}^{*}(g)\right)-\psi(g)+\beta \int_{\mathbb{G}}\left[\lambda W_{1}^{*}\left(g^{\prime}, B^{\prime}\right)+(1-\lambda) W_{0}^{*}\left(g^{\prime}\right)\right] \pi\left(d g^{\prime} \mid g\right),
$$

This economy is a nested case of AMSS with ad-hoc (state-contingent) borrowing limits under quasi-linear preferences, studied on page 1235 of AMSS. In the calibration, we set the utility penalty of defaulting in this model to match the average debt/GDP level in our baseline. In contrast with our baseline economy, the "Laffer curve" for bond proceedings has constant slope as long as additional borrowing is permitted by the solvency constraints (no "markup" on the bond price). A potential limitation of this bond economy pertains the inability of the government to provide some state contingency to its debt repayments (as is possible through the default option).

Model with Commitment to Default. The third economy is akin to our baseline model except for the fact that the government can commit to the default decision one period in advance. Cuadra and Sapriza [2008] and D'Erasmo [2011]), costs upon default associated with resource misallocation and financial disruptions (for instance, Mendoza and Yue [2012], Sosa-Padilla [2014]), and re-distributional motives (see D'Erasmo and Mendoza [2018] and Dovis et al. [2016]). Although we consider these issues important, we think they are out of the scope of the present paper and do not explore them herein.

${ }^{22}$ This model is similar to the bond economy with limited enforcement proposed in Bai and Zhang [2010]. 
The Bellman equation upon default is identical to that in the baseline. The value of repaying satisfies

$$
\begin{aligned}
W_{1}^{*}(g, B)= & \max _{\left(n, B^{\prime}, \bar{g}\right) \in \Gamma(g, B)}\{n-g+H(1-n) \\
& \left.+\beta\left[\int_{g_{\min }}^{\bar{g}}\left\{W_{1}^{*}\left(g^{\prime}, B^{\prime}\right) \pi\left(d g^{\prime} \mid g\right)+\int_{\bar{g}}^{g_{\text {max }}} W_{0}^{*}\left(g^{\prime}\right)\right\} \pi\left(d g^{\prime} \mid g\right)\right]\right\},
\end{aligned}
$$

with $\quad \Gamma(g, B)=\left\{\left(n, B^{\prime}, \bar{g}\right) \in[0,1] \times \mathbb{B} \times\left[g_{\min }, g_{\max }\right]: z(n, g)+\beta \int_{g_{\min }}^{\bar{g}} \pi\left(d g^{\prime} \mid g\right) B^{\prime}-B \geq 0\right\}$,

and the value of defaulting is given by 6.16. As can be seen in the Bellman equation above, the government here is not deciding whether to default or not next period based on just comparing the relative utility delivered next period from repaying against defaulting. Instead, the government chooses the default threshold $\bar{g}(g, B)$ optimally by maximizing current rather than next period's utility. In doing so, the government internalizes the effect of its default actions next period on current bond prices. The default strategy would typically be different than in our baseline model, reflecting a well-known time-inconsistency issue in the default literature. When choosing sequentially, the current administration does not take into account the impact of its default decision on prices faced by the previous administration.

While we assume here that the government can only commit to next-period default decision, it is easy to see that with one-period bonds the equilibrium is identical when the government has a commitment technology for all future default decisions. The proof for this equivalence between one-period-ahead commitment and full commitment for default is delegated to the appendix (see subsection D.2). As pointed out by Zame [1993], under commitment, the option to default here promotes efficiency under incomplete markets as it helps tailor securities to the borrower's needs.

As we will explore next in the numerical section, this alternative economy may shed light on how the lack of commitment for default affects the government's ability to borrow and smooth taxes.

\subsection{Calibration}

Throughout this section, we calibrate our model to Spain for the recent debt crisis and run a battery of numerical exercises in order to assess the impact of endogenous default risk on fiscal policy and the overall economy's dynamics. A period is a year. We compare our findings with the three alternative economies described in the previous subsection.

The main focus of the numerical results is to describe quantitatively some features pointed out in the normative analysis, and not to replicate business cycle dynamics of any particular economy or historical default event. The numerical simulations show that our model can spawn 
recurrent default episodes and is able to generate considerable levels of "debt intolerance" and high volatility of taxes.

Parametrization and functional forms. The utility term for leisure in the quasi-linear preferences has CRRA functional form, scaled by parameter $C_{1}>0$, i.e. $H(1-n)=C_{1} \frac{(1-n)^{1-\sigma}}{1-\sigma}$, with $\sigma>0$. In this parametrization, we assume that the government expenditure $g_{t}$ follows an $\operatorname{AR}(1) \log$-normal process

$$
\log g_{t}=\left(1-\rho_{g}\right) \mu_{g}+\rho_{g} \log g_{t-1}+\sigma_{g} \varepsilon_{t}, \text { with } \varepsilon_{t} \sim N(0,1),
$$

The stochastic process for $g_{t}$ is approximated by an 11-state Markov chain, using Tauchen [1986] procedure. $^{23}$

The utility penalty of default is parameterized as follows,

$$
\psi\left(g_{t}\right)=\max \left\{0, \eta_{0}-\eta_{1} g_{t}\right\} .
$$

Table 6.1: Model Calibration

\begin{tabular}{lcll}
\hline \hline Parameter & Value & Description & Target statistic/Source \\
\hline \multicolumn{2}{l}{ Calibrated parameters } & & \\
$\beta$ & 0.95 & Subjective discount factor & Literature \\
$\sigma$ & 1 & Coefficient of risk aversion & Literature \\
$C_{1}$ & 0.1 & Relative weight utility leisure & Literature \\
$\lambda$ & 0.5 & Reentry probability & Average autarky spell (2 years) \\
$\rho_{g}$ & 0.778 & AR(1) coefficient of $g_{t}$ & Spanish adj. govt. spending \\
$\sigma_{g}$ & 0.065 & Standard deviation of $\varepsilon_{t}$ & Spanish adj. govt. spending \\
\hline Parameters & set by simulation & \\
$\mu_{g}$ & -1.29 & Unconditional mean of $g_{t}$ & Share private consumption (60\% GDP) \\
$\eta_{0}$ & 0.0753 & Utility loss from default & Average bond spread (1\%) \\
$\eta_{1}$ & 0.032 & Utility loss from default & Average debt service (5.5\% GDP) \\
\hline \hline
\end{tabular}

Note: Adjusted government spending includes net exports. Total consumption is the sum of private consumption and adjusted government spending.

We calibrate our baseline model to match key features of Spain, an economy in which, first, government bond spreads have been non-negligible in recent years-reflecting some material

\footnotetext{
${ }^{23}$ For the baseline model, the debt state space $\mathbb{B}$ is constructed by discretizing $[0,0.5]$ into 301 gridpoints. For the alternative models, the debt grid is enlarged as much as needed. The one-period gross risk-free rate $1+r^{f}$ is equal to the reciprocal of the households' discount factor $\beta$. Finally, as in AMSS economies, we rule out negative lump-sum transfers to the households. The model is solved numerically using value function iterations with a discrete state space and an "outer" loop that iterates on prices until convergence.
} 
default risk-, and, second, a large fraction of government debt is held by residents. Table 6.1 shows the parameter values used in the calibration. We assign predetermined values to a set of parameters, and choose the remaining ones to match key targeted moments in the data.

The values of the predetermined parameters are taken from the standard taxation and default literature. The discount factor $\beta$ is set to 0.95, as in AMSS, which is also within the range of values assumed in the quantitative default literature. ${ }^{24}$ The coefficient of risk aversion on leisure $\sigma$ is 1 , as in AMSS and Farhi [2010]. The relative weight on the utility from leisure $C_{1}$ is broadly in line with the taxation literature. It is equal to 0.1, which lies in between the values of 0.05 and 0.75, considered by AMSS and Farhi [2010], respectively. The probability of regaining access to financial markets after a default $\lambda$ is set to 0.5 , which implies an average autarky spell of 2 years, in line with the evidence provided by Gelos et al. [2011] over the period 1980-2000 for 150 developing countries.

The parameter values for the government expenditure $\rho_{g}$ and $\sigma_{g}$ were estimated using a logquadratically detrended data for Spain from 1990 to 2014. In contrast, the drift parameter $\mu_{g}$ is set by simulations as explained below. Given that countries typically finance part of the large increases in government spending by borrowing externally we add net exports to government spending in the data. ${ }^{25}$

The values for the three remaining parameters, $\mu_{g}, \eta_{0}$ and $\eta_{1}$ are set to match three target statistics in the data. The first target statistic is the average fraction of private consumption in GDP, which in the data is roughly 60 percent for Spain. The second statistic is the average bond yield, which for Spanish bonds is roughly 1 for the period from 2000 to 2012. The last target statistic is the debt service, which amounted to 5.5 percent of GDP for domestic bonds. ${ }^{26}$

We perform 5,000 Monte Carlo (MC) iterations, each consisting of simulated paths of 2,000 observations for which the first 1,000 observations were disregarded in order to eliminate the effect of the initial conditions. To construct subsamples we try to replicate the build-up of the recent debt crisis for Spain in which bond spreads increased sharply peaking in 2012 until around Draghi's announcement that the ECB was ready to do "whatever it takes" to ease the

\footnotetext{
${ }^{24}$ The sensitivity of our quantitative results to the discount factor is relatively low compared to the standard quantitative default literature given that in our setup borrower and lenders exhibit the same degree of impatience.

${ }^{25}$ Data on real GDP, government spending, private consumption, exports and imports is taken from the National Statistics Office (INE). Data on employment and tax revenues is from the OECD database. All the time series, except the trade data but including the adjusted government spending (including net exports), are logged and filtered with a log-quadratically trend.

${ }^{26}$ Debt service is computed as follows. From 2000 to 2012, Spanish government debt held by domestic creditors was about 35 percent of GDP. Given the average maturity of 6.3 years observed in the data, we have a maturityadjusted debt ratio or debt service of around 5.5 percent of GDP. Data on domestic debt and debt maturity is from the OECD database. Bond spreads are computed as the difference of 5-year sovereign bond yields for Spain and Germany. The time series for bond yields are taken from Bank of Spain and Deutsche Bundesbank.
} 
Euro debt crisis. It is our view that this announcement showed a credible commitment by the ECB to assist countries in distress if required, a feature absent in our model, which played a key role in reducing market concerns, leading to a substantial decline of bond spreads thereon. Spain (and every other peripheral country) did not default after the announcement. For that reason, we focus on the period through 2012 and consider 1,000 subsamples, each of 20 periods of access to financial markets, in which spreads exceeded 3 percent in the last two periods, as observed in the data for 2011 and 2012. ${ }^{27}$. We then compute the statistics across these subsamples.

Since in general bond spreads increase along with government expenditure, by focusing on subsamples with repayment we are implicitly conditioning the paths for the exogenous government spending for our MC statistics. To preserve consistency when comparing our results with alternative economies, we impose the same subsample paths when computing statistics in the alternative economies.

For the risk-free debt economy with solvency constraints, we calibrate the parameter $\eta_{0}$ controlling for the utility penalty to match the same average debt-to-output ratio as in the baseline model. All other parameters remain unchanged.

We believe that the comparison against these alternative economies may shed some light on the effect of state contingency of the government's financing due to the possibility of default.

Table 6.2 presents the statistics for our baseline model and the three alternative economies. Our baseline model does a fair job matching some key non-targeted features of the data. Indeed, it is able to generate a high volatility of consumption relative to output and volatile and countercyclical interest rates, a salient feature of emerging economies.

Behavior of debt. Households in our baseline model anticipate the default strategies in equilibrium and demand higher returns to hold the bond. Facing higher borrowing costs, the government responds by issuing less debt. Consequently, the average level of indebtedness is significantly lower in our environment than in AMSS model with natural debt limits: debt/GDP is on average over six times lower in the baseline, as reported in table 6.2. Figure 6.1 illustrates this finding. The histograms (which were smoothed using kernel methods) of debt-to-output ratios in our model (solid red) and in AMSS (dotted blue) are shown for three different values of the government expenditure: low, intermediate and high. ${ }^{28}$ First, as the government expenditure increases, in both economies more debt is optimally chosen in order to finance it due

\footnotetext{
${ }^{27}$ In reality countries typically exit financial autarky carrying a positive amount of restructured debt while in our model the government does so with no liabilities. For that reason, we also disregard the 4 periods that follow reentry to financial markets. The unconditional default frequency is computed as the sample mean of the number of default events in all the simulations.

${ }^{28}$ To construct the histograms we collect one million periods with financial access in the simulations. Low (High) government expenditure correspond to one unconditional standard deviation below (above) the unconditional mean; the intermediate value is the unconditional mean.
} 
Table 6.2: MC Statistics for Models And Data.

\begin{tabular}{|c|c|c|c|c|}
\hline Statistic & $\begin{array}{c}\text { Baseline } \\
\text { Model }\end{array}$ & $\begin{array}{l}\text { Risk-free bond with } \\
\text { solvency constraints } \\
\text { (SC) }\end{array}$ & $\begin{array}{l}\text { Risk-free bond with } \\
\text { natural debt limits } \\
\text { (AMSS) }\end{array}$ & $\begin{array}{c}\text { Commitment } \\
\text { to default } \\
\text { (CD) }\end{array}$ \\
\hline Mean(debt service) $(\%$ GDP $)$ & 5.49 & 5.5 & 35.6 & 48.8 \\
\hline $\operatorname{Mean}\left(r-r^{f}\right)(\%)$ & 1.41 & 0 & 0.0 & 0.03 \\
\hline $\operatorname{Mean}(\tau)$ & 0.358 & 0.357 & 0.359 & 0.363 \\
\hline $\operatorname{Std} \cdot \operatorname{dev} \cdot(\tau)$ & 0.042 & 0.040 & 0.025 & 0.021 \\
\hline Autocor. $(\tau)$ & 0.830 & 0.35 & 0.38 & 0.39 \\
\hline Std.dev.(y) & 0.013 & 0.012 & 0.008 & 0.007 \\
\hline Std.dev.(c) & 0.080 & 0.079 & 0.071 & 0.069 \\
\hline $\operatorname{Std} \cdot \operatorname{dev} \cdot\left(r-r^{f}\right)$ & 2.900 & 0 & 0.000 & 0.06 \\
\hline Std.dev.(debt) & 0.024 & 0.023 & 0.095 & 0.110 \\
\hline Std.dev.(debt/GDP) & 0.029 & 0.027 & 0.115 & 0.134 \\
\hline $\operatorname{corr}(\mathrm{y}, \mathrm{c})$ & 0.98 & 0.98 & 0.92 & 0.91 \\
\hline $\operatorname{corr}\left(\mathrm{y}, r-r^{f}\right)$ & -0.83 & 0 & 0 & -0.28 \\
\hline $\operatorname{corr}\left(\tau, r-r^{f}\right)$ & 0.79 & 0 & 0 & 0.27 \\
\hline $\operatorname{corr}(\tau, \mathrm{g})$ & 0.96 & 0.96 & 0.88 & 0.87 \\
\hline 20th-percentile $(\tau)$ & 0.322 & 0.322 & 0.338 & 0.344 \\
\hline 80th-percentile $(\tau)$ & 0.393 & 0.393 & 0.378 & 0.379 \\
\hline $\operatorname{Std} \cdot \operatorname{dev} \cdot(\tau \mid$ low debt $)$ & 0.033 & 0.031 & 0.023 & 0.022 \\
\hline Std.dev. $(\tau \mid$ high debt $)$ & 0.039 & 0.035 & 0.029 & 0.028 \\
\hline $\operatorname{mean}(\tau \mid$ low debt $)$ & 0.328 & 0.327 & 0.334 & 0.338 \\
\hline $\operatorname{mean}(\tau \mid$ high debt $)$ & 0.388 & 0.387 & 0.383 & 0.388 \\
\hline Std.dev.(bond proceeds|low debt) & 0.008 & 0.009 & 0.022 & 0.024 \\
\hline Std.dev.(bond proceeds|high debt) & 0.007 & 0.005 & 0.022 & 0.025 \\
\hline mean(bond proceeds|low debt) & 0.002 & 0.003 & 0.006 & 0.005 \\
\hline mean(bond proceeds|high debt) & -0.004 & -0.003 & -0.009 & -0.014 \\
\hline
\end{tabular}

Note: In the risk-free debt economy with solvency constraints, the parameter $\eta_{0}$ for the utility penalty of default is calibrated to generate the same average debt/GDP as in the baseline model. For the conditional statistics, low and high debt correspond to debt levels below and above the median over all the subsamples. Bond proceeds are defined as $q_{t} B_{t+1}-B_{t}$. 
to tax-smoothing motives. In addition, the debt-to-output ratio in our model becomes more concentrated the higher the value of $g$ is. This clustering feature is due to the fact that, as $g$ increases, the government wants to issue more debt, but faces tighter (endogenous) borrowing limits resulting from higher default risk. This behavior is in stark contrast with the one for AMSS, where the debt-to-output ratios are more spread out and can take higher values. In fact, for the bottom panels there is almost full separation between the histogram of our model and that of AMSS. It is worth to note as well, that even for low values of $g$ (e.g. the top panel) our model exhibits "thinner right tail" for the distribution of debt-to-output ratio, again illustrating the latent borrowing limits. ${ }^{29}$

The inability to commit to a default strategy plays an important role in the debt and default dynamics, and therefore on the volatility of taxes in the economy. To understand this, in the model with commitment to default we take the envelope condition with respect to current debt $B$ and the first order condition with respect to the default threshold $\bar{g}(g, B)$,

$$
\begin{array}{r}
\frac{\partial W_{1}^{*}(g, B)}{\partial B}=-\nu(g, B)<0 \\
W_{1}^{*}\left(\bar{g}(g, B), B^{\prime}(g, B)\right)-W_{0}^{*}(\bar{g}(g, B))=-\nu(g, B) B^{\prime}(g, B)
\end{array}
$$

where $\nu(g, B)$ is the Lagrange multiplier associated to the government's implementability constraint. The other optimality conditions are the same as in our baseline model. Some important insights from equation 6.19 follow. In our baseline model, the default threshold makes the government indifferent between repaying or not, i.e. $W_{1}^{*}\left(\bar{g}(g, B), B^{\prime}(g, B)\right)=W_{A}^{*}(\bar{g}(g, B))$. In contrast, if the government can commit to default, $W_{0}^{*}(\bar{g}(g, B))>W_{1}^{*}\left(\bar{g}(g, B), B^{\prime}(g, B)\right)$, as implied by equation 6.19 , which means that the equilibrium default sets $D(B)$ are contained in those from the baseline economy. Essentially, the lack of commitment induces more default in our baseline, which in turn is reflected in lower prices of the government bond. Facing higher borrowing costs, the government borrows relatively less in equilibrium, resulting in more tax variability. Not surprisingly, in our simulations we observe significantly higher levels of indebtness, lower bond spreads (and default frequency) and lower tax volatility in the economy wherein the government can commit to future default decisions than in our baseline. ${ }^{30}$ Finally, if we compare the simulation results from AMSS with the model with commitment to default, we see that the latter sustains higher debt in equilibrium despite the occasionally-positive bond

\footnotetext{
${ }^{29}$ For sufficiently high $g$ realizations, the debt histogram may shift to the right as current $g$ increases. This may occur for two reasons. First, for higher $g$, the utility penalty of default may fall enough to lead to tighter endogenous credit limits. Second, there may be selection bias since for high debt and high $g$ the government may prefer to default, and hence those observations are excluded from these histograms.

${ }^{30}$ Some of these results echo the findings by Adam and Grill [2017]. In their neoclassical small open economy, the Ramsey optimal policy under full commitment prescribes default on the external debt only for disaster-like shocks to productivity.
} 
(a) low $g$

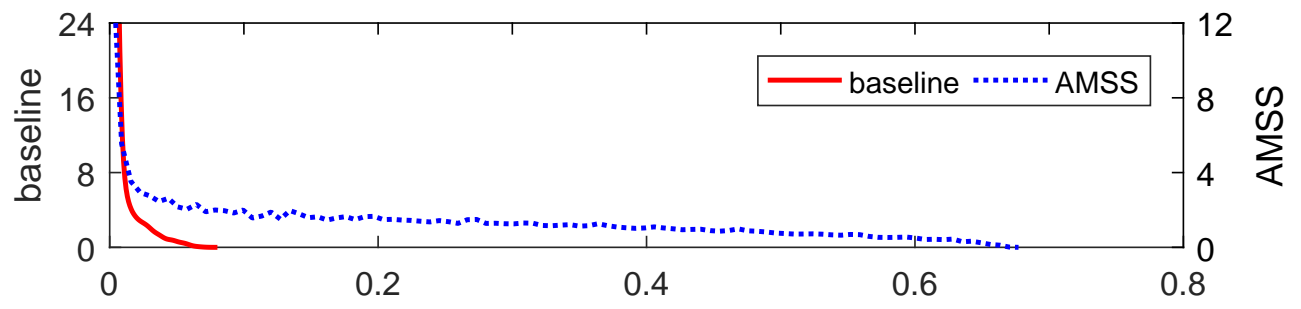

(b) intermediate $g$

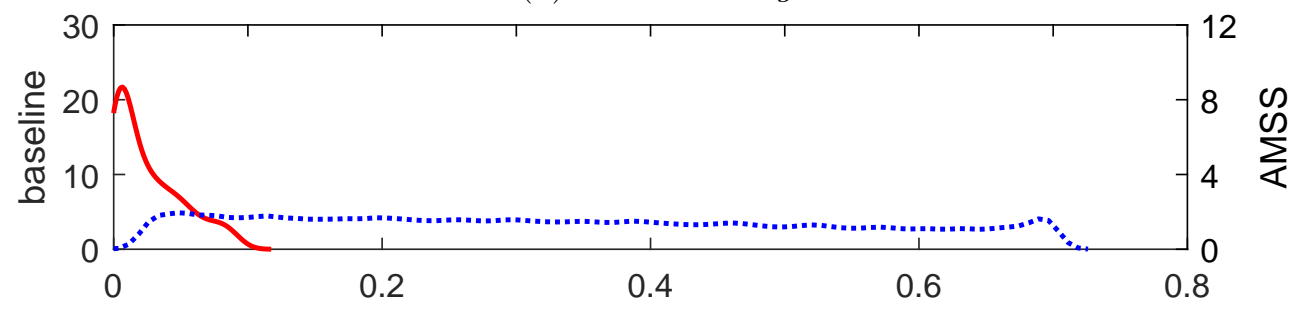

(c) high $g$

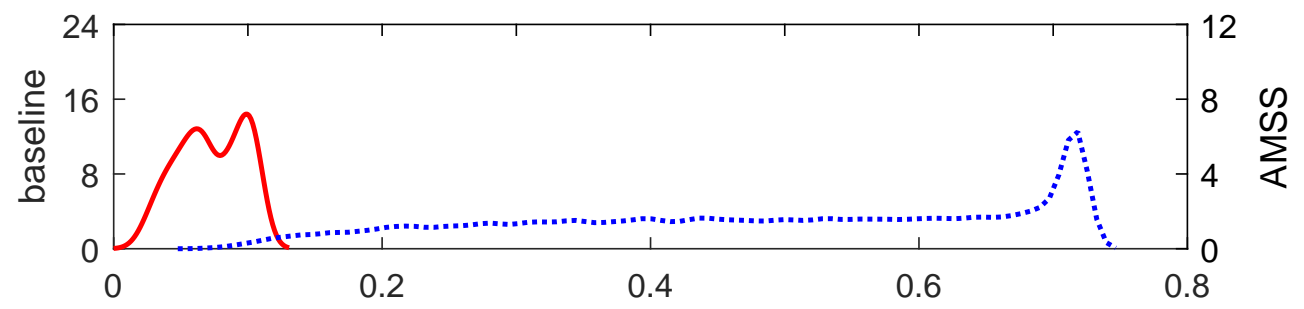

Figure 6.1: Histograms of debt-to-output ratio in financial access for baseline model and AMSS with natural debt limits.

Notes: The dotted blue lines are histograms of debt-to-output ratio for AMSS with natural debt limits, solid red lines are histograms for baseline model. Low (high) value of $g$ is one unconditional standard deviations below (above) the unconditional mean; intermediate value is the unconditional mean. Histograms were smoothed using kernel methods.

spreads. More borrowing reflects the benefits of the option to default: it helps complete the financial markets, expanding the borrowing opportunities for the government, particularly in times with high government expenditure and/or high debt. A clear implication of it is lower tax variability and higher welfare.

Behavior of taxes. As mentioned in section 5, we typically observe in the data that default risk and tax volatility are positively correlated and that both are higher for high levels of debtto-output ratio. Figure 6.2 shows that our model is able to generate this pattern. The blue (red) dots indicate the standard deviation of taxes and spreads for low (high) levels of debt, respectively. Each dot corresponds to the subsample of periods with financial access in a MC 


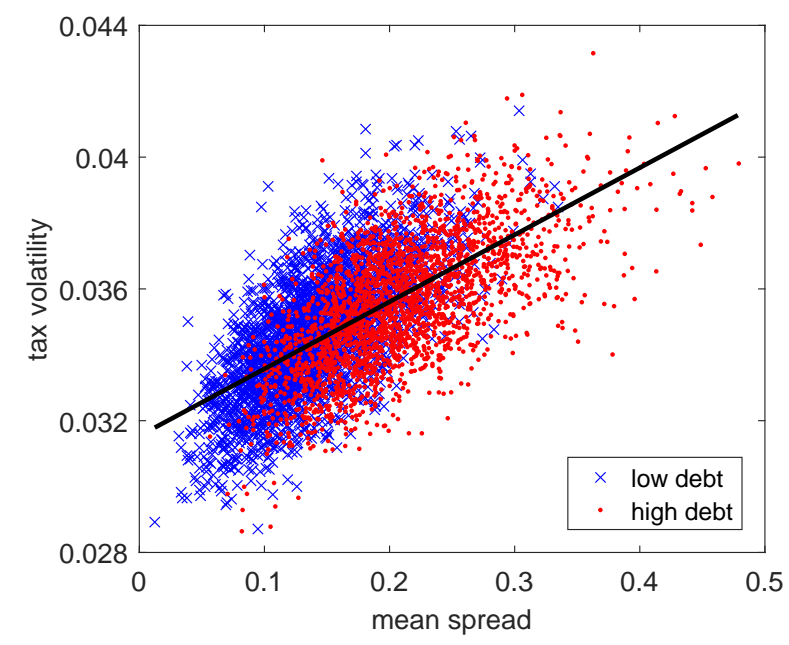

Figure 6.2: Tax volatility vs. mean bond spreads in financial access.

Note: Tax volatility is measured as standard deviation of the tax rate. Each marker corresponds to one MC simulation. For each simulation, we compute tax volatility and mean bond spread over all the periods with financial access. Markers in red (low debt) correspond to simulations with average debt-to-GDP ratio below the median across simulations, and markers in blue (high debt) correspond to simulations with average debt-to-GDP ratio above the median across simulations. The black line is the OLS estimate.

simulation. The solid black line represents the regression line. For low (high) debt we consider debt-to-output ratios below (over) the median of its asymptotic distribution. For both cases we see a positive relationship between spreads and tax volatility, reflecting the government's limited ability to spread out the tax burden across time in the context of default risk. The estimated slope in the OLS regression is 2.04 percent, which implies that a one-percent increase in average bond spread implies an increase in tax volatility of around 50 percent relative to its sample mean. ${ }^{31}$ Another feature that stands out in figure 6.2 is that the red dotted-cloud is shifted to the upper right corner of the graph with respect to the blue crossed-cloud, thus indicating that both spreads and tax volatility are higher for higher level of debts.

As reported in table 6.2, in the simulations the standard deviation of tax rates in financial access is 70 percent higher than in AMSS with natural debt limits. Similarly, the 20th-80th percentile band is wider and contains its counterpart in the latter economy. Essentially, as reflected by the tax and debt histograms, the possibility of default gives rise to endogenous credit limits that hinder the government's ability to spread the tax burden over time and across states. The possibility to smooth taxes further thank to the expanded state contingency of bond payoffs (provided by the option to default) is overturned by the costs involving the limited borrowing capacity of the government.

\footnotetext{
${ }^{31}$ The slope of the OLS fitted line is statistically significant. The associated t-statistic is over 60 .
} 
(a) low $g$

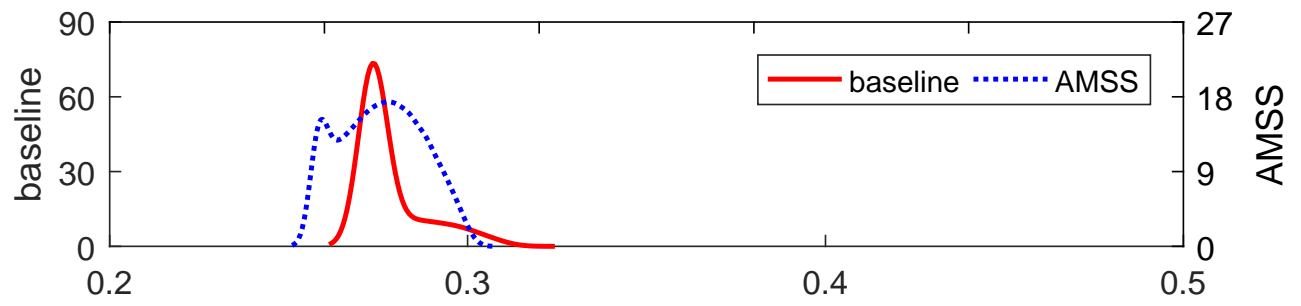

(b) intermediate $g$

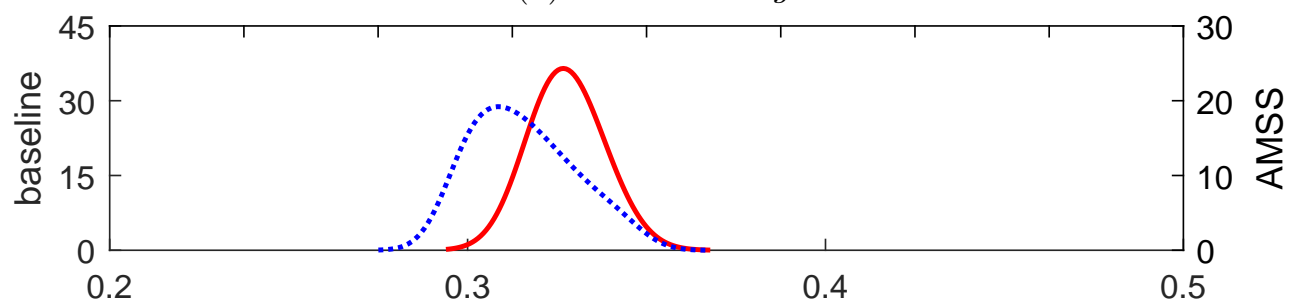

(c) high $g$

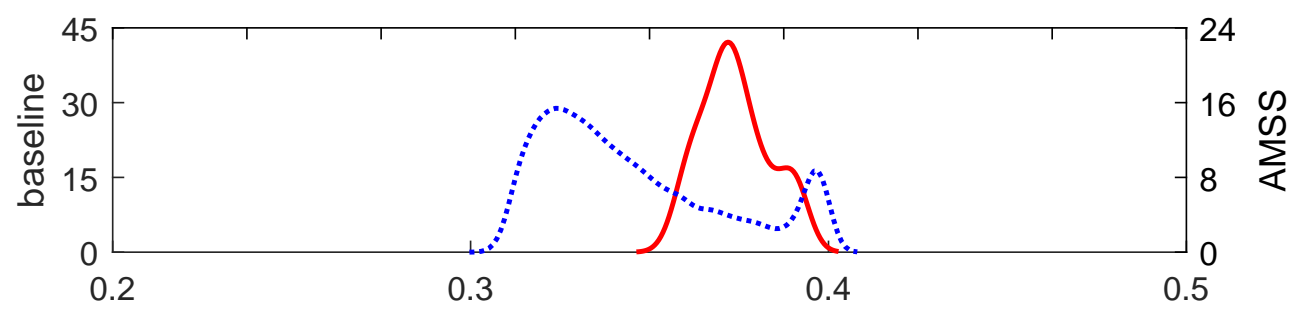

Figure 6.3: Histograms of taxes in financial access for baseline model and AMSS with natural debt limits.

Notes: The dotted blue lines are histograms of tax rates for AMSS with natural debt limits, solid red lines are histograms for baseline model. Low (high) value of $g$ is one unconditional standard deviations below (above) the unconditional mean; intermediate value is the unconditional mean. Histograms were smoothed using kernel methods.

In order to shed more light about the behavior of taxes when there is risk of default, we compare in figure 6.3 the histograms (again smoothed using kernel methods) of tax rates in our model (solid red) with that in AMSS (dotted blue), for three different values of government expenditure. Low (high) value of $g$ is one unconditional standard deviations below (above) the unconditional mean; the intermediate value is the unconditional mean. First, as observed in the bottom panel, for a high value of $g$, the distribution of taxes in our model is shifted to the right compared to that in AMSS model. This difference arises from the fact that in our environment, with default risk, debt is too costly for the government to finance high government expenditure and hence it has to resort to higher tax rates. In contrast, in the top panel, when the $g$ realization is low, the situation is reversed and now the distribution of taxes in AMSS 
model is shifted to the right relative to our model. During those states, the government repays the outstanding debt, which typically is higher in AMSS than in our credit-constrained economy. In addition, in our model taxes are more concentrated around a single peak (which shifts to the right with the level of government expenditure), reflecting more limited borrowing. In contrast, in AMSS the distribution of taxes is more spread-out for each $g$ realization but at the same time is less sensitive to changes in $g$, a clear reflection of more tax smoothing.

Figure 6.4 plots the Lagrange multipliers associated to the government's budget constraint -which can be interpreted as the tax distortion in the economy-for all the economies, as function of $g$. In the top panel the current debt is zero and in the bottom panel is equal to the average in the simulations of the baseline model. As mentioned before, equilibrium allocations for labor and hence taxes- can be directly mapped to these multipliers $\nu$. Higher values of $\nu$ are associated to high values of taxes. For low $g$ realizations, tax distortions are basically the same across all the economies and vary little with $g$, as the government is able to smooth taxes through pretty much unconstrained borrowing. In contrast, for moderate or high $g$, tax distortions in the baseline rise sharply with $g$ as default risk (next period or the near future) mounts. To a lesser extent, that feature is also observed in the economy with solvency constraints, as it becomes more likely that the borrowing limits to bind, forcing the government to raise taxes.

A direct implication from this figure is that taxes are more volatile for both low and high debt levels in our baseline model than in all alternative economies, which is also shown in table 6.2. This seems consistent with the fact that bond proceeds, defined as $q_{t} b_{t+1}-b_{t}$, are relatively less variable due to the emergence of endogenous credit limits. Tax volatility rises when debt is high in all economies. As explained before, labor and taxes are more sensitive to fluctuations in government expenditure due to the concavity of the primary surplus function $z(\cdot, g)$ in $n$, when net bond payments are large. This is the case for all economies when debt is high as bond proceeds are on average negative and large, as reported in the table. In our baseline, this effect is not so dominant in explaining the gap in tax volatility as in AMSS and the model with commitment to default because average bond proceeds while still negative are closer to zero. There is a second effect, however, that plays a more critical role: bonds spreads are higher and more volatile, and debt limits are tighter, as reflected in less variable bond proceeds when debt is high.

Yet, the tighter borrowing limits do not explain the entire difference in tax volatility across all economies. Once we control for the same average indebtness level, as featured in the risk-free bond economy with solvency constraints, we observe that the standard deviation of taxes is still 5 percent higher in the baseline model. This discrepancy is smaller than relative to AMSS but considerable given that under quasi-linear preferences households do not mind absorbing large fluctuations in consumption while the government smoothes taxes and labor in response 
(a) low debt

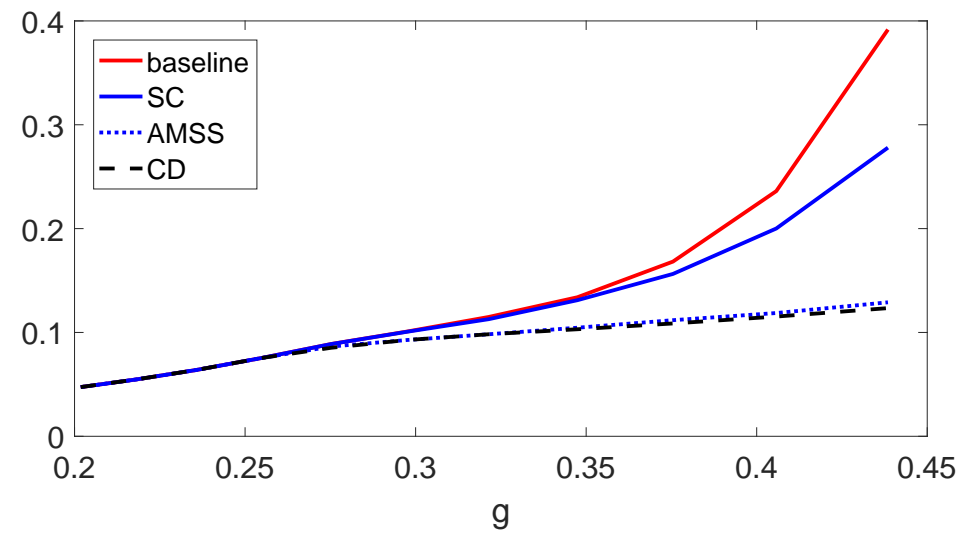

(b) high debt

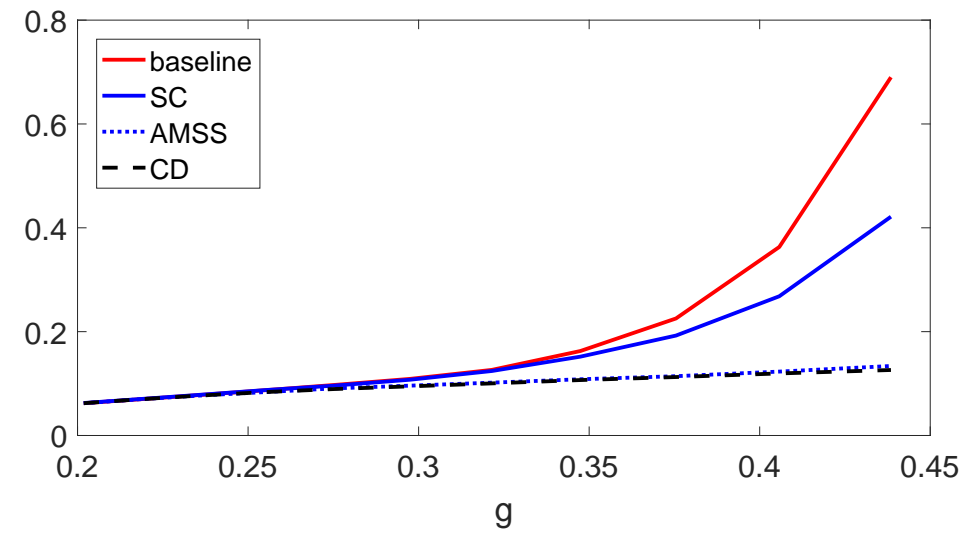

Figure 6.4: Tax distortions in baseline and alternative models, as function of $g$.

Notes: Tax distortions are represented by the Lagrange multipliers $\nu$ associated with the government's implementability constraint. Low debt corresponds to zero debt. High debt corresponds to the average debt level in the baseline.

to government expenditure shocks. ${ }^{32}$ Higher borrowing costs due to default risk particularly when financing needs are substantial due to high government expenditure seem to explain a non-negligible fraction of the gap in tax volatility.

Impulse responses. Figure 6.5 presents the simulated paths for taxes, the lagrange multiplier on the government budget constraint, fiscal balance and newly-issued debt for a given path

\footnotetext{
${ }^{32}$ Indeed, the standard deviation of consumption in our baseline economy is 1.25 percent higher than in the risk-free bond economy with solvency constraints, and 11.25 percent higher than in AMSS with natural debt limits. A related implication of quasi-linear preferences is that the government is quite reluctant to default in this economy because, first, households can absorb any sharp increase in bond supply as long as consumption remains non-negative, and, second, they do not charge any risk premium on government bonds on top of the risk-neutral compensation to bear the default risk.
} 
of government expenditure, for the baseline and the three alternative economies. The path of government expenditure is plotted in the first panel. The initial debt level is set to zero. As shown in the bottom panel, while in all economies the government accumulates debt in periods of higher government expenditure, in our model and in the risk-free debt model with solvency constraints it does so to a lesser extent due to the presence of tight borrowing limits. From $t=4$ onwards, when government expenditure starts declining, the debt is gradually paid back, eventually reaching zero in the baseline.

Taxes behave analogously: in our economy taxes are higher during the periods of high government expenditure since borrowing is more limited and costly, but decrease more rapidly when the realization of government expenditure becomes lower (see panel (b)). The peak in taxes is 3 percentage points lower in the bond economy with solvency constraints: while the quantity of newly-issued debt is quite similar, bond proceeds are considerably smaller in our baseline as bond spreads reach 32 percent.

Overall, not surprisingly, a smoother behavior for taxes is observed in AMSS and in the model with commitment to default than in our economy, resulting from the absence of default risk -endogenous outcome wen the government can commit-. In all economies, a hike in the tax rate reduces after-tax wages inducing substitution from labor to leisure (recall that with quasi-linear preferences the labor supply curve is invariant to changes in wealth). Consequently, output drops. Debt is more persistent than tax rates, a feature that stands out under incomplete markets, as stressed by Marcet and Scott [2009]. Also, in line with the findings of Marcet and Scott [2009], all economies experience a significant fiscal deficit as $g$ increases and debt grows (see panel (d)). In AMSS and in the model with commitment to default, since the government has more borrowing capacity, it issues more debt, and hence the fiscal deficit in the short run is relatively larger.

Panel (c) plots the behavior of the Lagrange multiplier $\nu_{t}$ of the implementability constraint, studied in subsection 5.1. Again, the fact that ours is above the one of the risk-free bond model with solvency constraints for periods of high government expenditure reflects the "mark-up" effect mentioned in subsection 5.1. Also note that the Lagrange multiplier increases during these periods, reflecting the fact that the shadow cost of debt is increasing in the level of debt. From $t=4$ onwards, as debt decreases, the Lagrange multiplier in our model falls and eventually converges to the one in the other economies. 
(a) government expenditure $(g)$

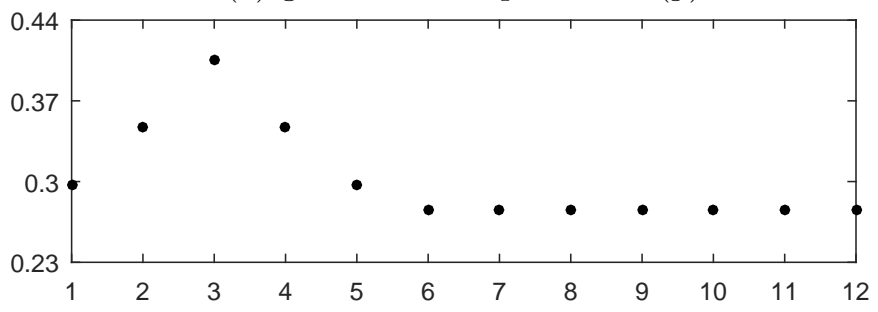

(b) $\operatorname{tax}(\tau)$

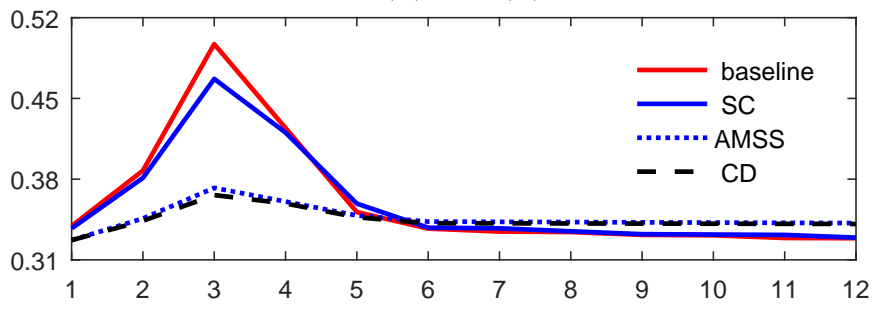

(c) lagrange multiplier $(\nu)$

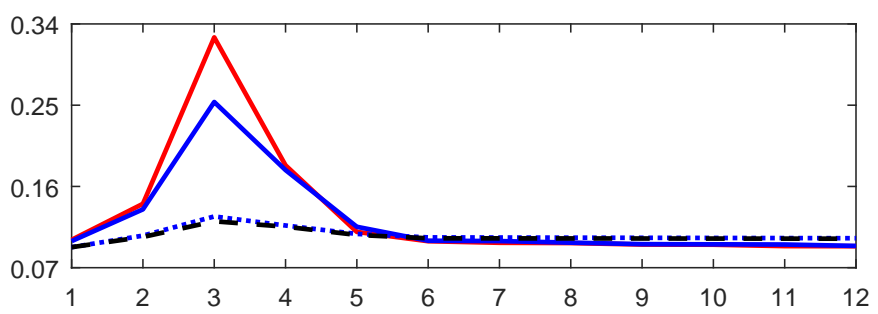

(d) fiscal balance $(z)$

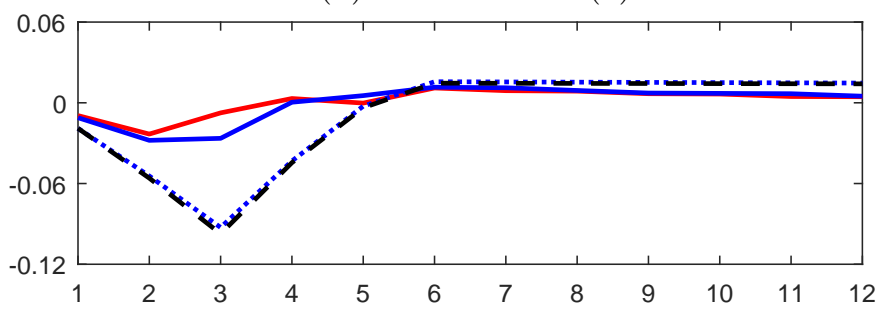

(e) $\operatorname{debt}\left(b^{\prime}\right)$

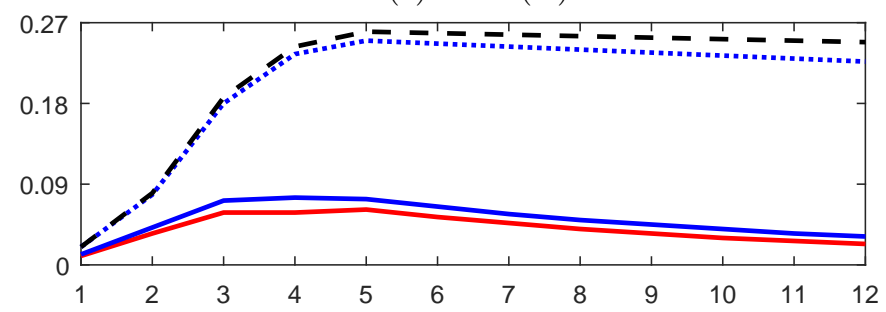

Figure 6.5: Impulse responses for baseline model and alternative economies.

Notes: Tax, lagrange multiplier on the government budget constraint, fiscal balance and new debt for a given path of government expenditure, in baseline and all the alternative economies. The initial debt level is set to zero.

Welfare. We proceed next to compare welfare across the different economies. We compute welfare gains of moving to an arbitrary alternative economy as the permanent increase in 
consumption in all the states of nature that would make the government indifferent between living in our baseline model and switching to that alternative economy. ${ }^{33}$ Table 6.3 reports ex ante welfare gains for the case with zero initial debt. Some observations are in order. First, welfare gains from eliminating default risk while keeping similar average debt (through stringent credit limits) are quite sizable reaching almost 0.01 percent. While overall borrowing is similar to that in the economy with solvency constraints, the government in the baseline model issues relatively less debt in states associated with high default risk next period in response to high borrowing costs. Slightly more stringent credit limits coupled with sizable bond spreads explain why welfare is lower in the baseline. Second, welfare gains of moving to AMSS economy are over five times larger. Relaxing the borrowing limits improves welfare substantially as more tax smoothing takes place. Finally, allowing the government to commit to the default strategy renders even higher utility to the government than in AMSS with natural debt limits. This reflects the positive role of default in promoting efficiency when asset markets are incomplete, despite the inefficiencies associated to it. The difference in welfare gains between the two economies is, however, little, as the government rarely defaults when it internalizes the effects of doing so on its borrowing costs.

\section{Table 6.3: Welfare Gains.}

\begin{tabular}{lccc}
\hline \hline & $\begin{array}{c}\text { Risk-free bond with } \\
\text { solvency constraints } \\
(\mathrm{SC})\end{array}$ & $\begin{array}{c}\text { Risk-free bond with } \\
\text { natural debt limits } \\
\text { (AMSS) }\end{array}$ & $\begin{array}{c}\text { Commitment } \\
\text { to default } \\
(\mathrm{CD})\end{array}$ \\
\hline Welfare gains $(\%)$ & 0.0087 & 0.0541 & 0.0573 \\
\hline \hline
\end{tabular}

Note: Welfare gains of moving to an alternative economy are expressed as the permanent increase in consumption in all the states of nature that would be make the government indifferent between living in our baseline model and switching to that alternative economy. Welfare gains are ex ante gains for the case of zero initial debt.

Figure 6.6 plots conditional welfare gains, as function of current $g$, for zero current debt. Welfare gains for the three alternative economies are positive and increasing in $g$. For high $g$ realizations, the welfare gains of moving to the economy with solvency constraints are around 0.07 percent while the welfare gains of switching to any of the two other economies exceed 0.25 percent. In our baseline, the higher the current government expenditure, the more likely default occurs next period (or in subsequent periods). Consequently, the government is expected to face difficulties issuing large amounts on debt while keeping borrowing costs low, which in turn interferes with its ability to smooth taxes. As mentioned earlier, even relative to the economy

\footnotetext{
${ }^{33}$ Welfare gains are computed using value function iteration.
} 


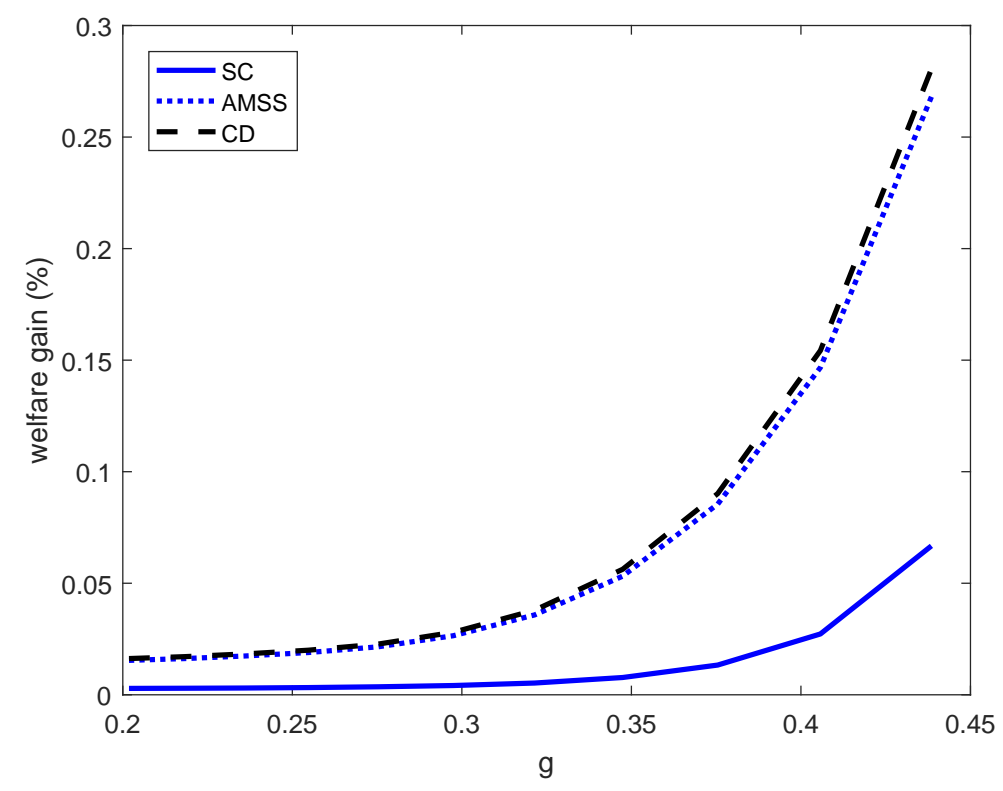

Figure 6.6: Welfare gains of switching to alternative economies.

Note: Welfare gains of moving to an alternative economy are expressed as the permanent increase in consumption in all the states of nature that would be make the government indifferent between living in our baseline model and switching to that alternative economy. The current debt level is set to zero.

with solvency constraints, credit limits in the baseline are tighter for those states with high $g .{ }^{34}$

Dynamics around default episodes. To better understand the role of default and its implications for fiscal policy, we show here the evolution of taxes around a 9-period window around the default event. To do so, we pick 1,000 default episodes in our simulations that were preceded by at least 6 periods of access to financial markets and that were followed by at least 4 periods of financial exclusion. Figure 6.7 presents the dynamics of the cross-sectional medians of government expenditure, tax, consumption, labor, debt and bond spreads around these default events. We also compute the counterfactual levels assuming that the government is not allowed

\footnotetext{
${ }^{34}$ It is not easy to decouple the contribution to welfare coming from the more stringent credit limits and the higher borrowing costs. We can decompose, however, the difference in bond proceeds between the baseline and the risk-free debt model with solvency constraints, for any arbitrary state of the economy. For instance, for zero current debt and the highest $g$ realization, we find bond proceeds are 87 percent higher in the risk-free debt model with solvency constraints. In this economy, while that the quantity of newly issued bonds is 57 percent higher, bond prices are 19 percent higher. For lower $g$ realizations, the overall contribution of bond prices in the difference of bonds proceeds is lower. We have also considered an alternative risk-free bond economy in which state-contingent borrowing limits are set to the equilibrium debt choices in the baseline for each state of the economy. In the simulations for such an economy, tax volatility is 3 percent lower than in the baseline whereas average debt/GDP is 23 percent smaller. The welfare gain with respect to this alternative economy is 0.022 percent, about a third of the welfare gain with respect to the risk-free debt economy.
} 
to default. ${ }^{35}$

As shown in the top panel, government expenditure increases in the run-up to the default, peaking in the period of the announcement. Taxes rise along to finance the increasing government expenditure and the growing debt built over time. In period 0 the government finds optimal to default and tax rates decline thereafter. Had the government not defaulted, as indicated y the counterfactual, taxes would have jumped by over 10 percent. The fact that the tax rate is lower upon defaulting than in the counterfactual scenario follows from lemma D.2 in the appendix. This lemma shows that in the states in which default is optimal, if the government had repaid, it would not have been able to raise any funds from the debt management for any available debt contract. Rather, it would be subject to additional outlays. Consequently, taxes would necessarily be higher in that case. Thus, by defaulting, the government avoids transiently higher tax distortions. As expected, taxes after $t=0$ decline gradually, given the high outstanding debt that the government has to repay.

\footnotetext{
${ }^{35}$ For the counterfactual, we exclude those cases in which forcing the government to repay in the default period violates the government's budget constraint or the constraint for non-negative consumption.
} 
(a) government expenditure $(g)$

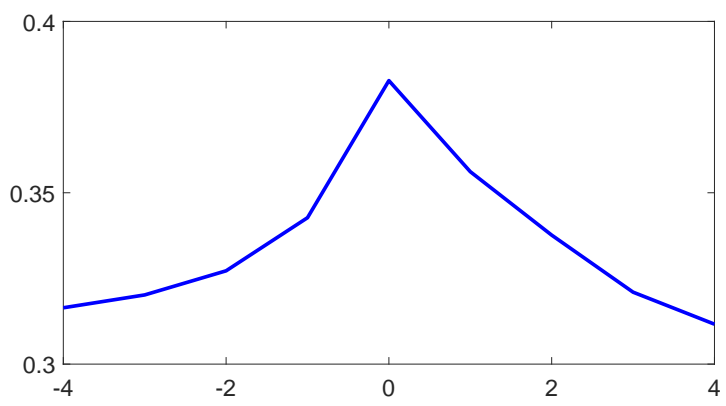

(c) labor $(n)$

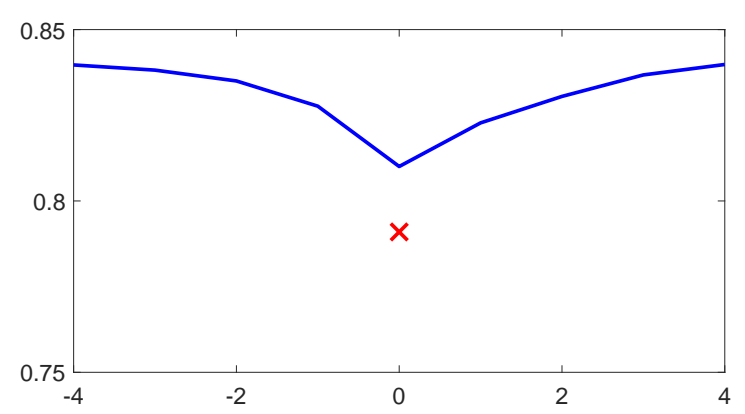

(e) debt $\left(b^{\prime}\right)$

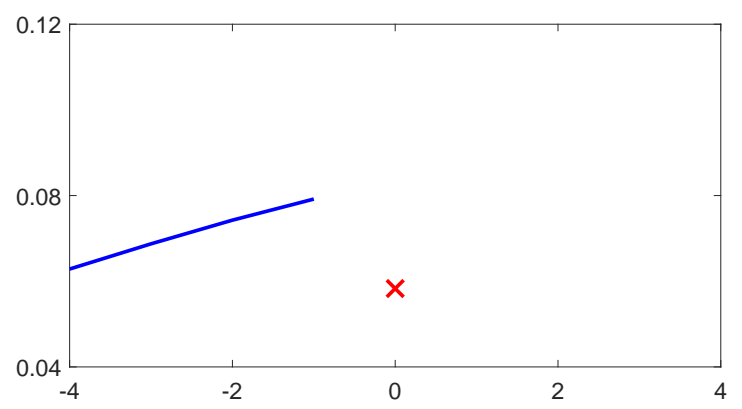

(b) $\operatorname{tax}(\tau)$

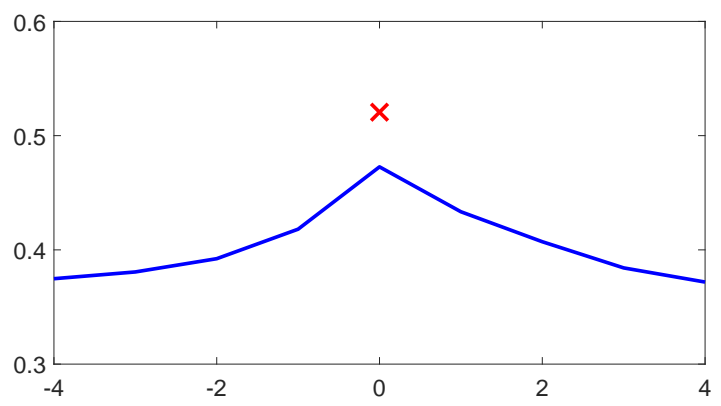

(d) consumption (c)

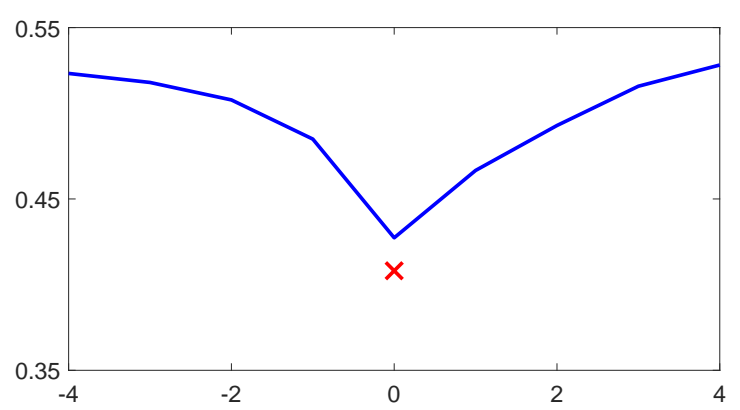

(e) spreads $\left(r-r^{f}\right)$

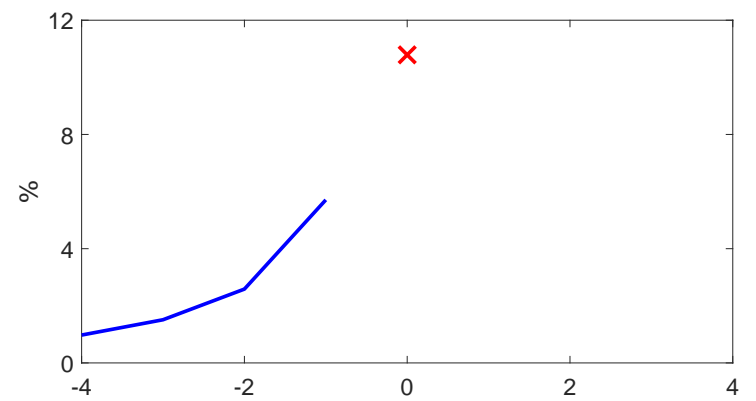

Figure 6.7: Default episode windows in model simulations.

Notes: Solid lines correspond to cross-sectional medians of model simulations around default episodes for government expenditure, tax, consumption, labor, debt and bond spreads. The default announcements take place in period zero. Red markers correspond to counterfactual levels if the government is forced to repay in the default period.

\section{Conclusion}

Our model extends the results on optimal taxation under incomplete markets results to environments where the government can default on its debt. We study how default risk and the actual default event affect tax policies and vice-versa. By defaulting the government avoids higher tax distortions in the future that would come along with the service of the debt. The 
presence of default risk, however, gives rise to endogenous credit limits that can hinder the government's ability to smooth shocks using debt. As a result, taxes may become more volatile than in the standard incomplete market setting. We view our model as a suitable framework to study government policies for economies that are (or were) prone to default and to restructure their debt. Some examples throughout history include France and the U.S. in the 18th century, and emerging economies nowadays.

\section{References}

K Adam and M Grill. Optimal sovereign default. American Economic Journal: Macroeconomics, 9(1):128-164, 2017.

M Aguiar and G Gopinath. Defaultable debt, interest rates and the current account. Journal of International Economics, 69(1):64-83, 2006.

M Aguiar, M Amador, and G Gopinath. Investment cycles and sovereign debt overhang. Review of Economic Studies, 76(1):1-31, 2009.

R Aiyagari, A Marcet, T Sargent, and J Seppälä. Optimal taxation without state contingent debt. Journal of Political Economy, 110:1220-1254, 2002.

G M Angeletos. Fiscal policy with non-contingent debt and the optimal maturity structure. Quarterly Journal of Economics, 117:1105-1131, 2002.

C Arellano. Default risk and income fluctuations in emerging economies. American Economic Review, 98(3):690-713, 2008.

Y Bai and J Zhang. Solving the feldstein-horioka puzzle with financial frictions. Econometrica, 78(2):603-632, 2010.

R J Barro. On the determination of the public debt. Journal of Political Economy, 87(5):940-71, 1979.

S Bauducco and F Caprioli. Optimal fiscal policy in a small open economy with limited commitment. Journal of International Economics, 93(6), 2014.

A Bhandari, D Evans, M Golosov, and T Sargent. Fiscal policy and debt management with incomplete markets. Quarterly Journal of Economics, 132(2):617-663, 2017.

F Buera and J P Nicolini. Optimal maturity of government debt without state contingent bonds. Journal of Monetary Economics, 51:531-554, 2004. 
G Cuadra and H Sapriza. Sovereign default, interest rates and political uncertainty in emerging markets. Journal of International Economics, 76(1):78-88, 2008.

G Cuadra, J M Sanchez, and H Sapriza. Fiscal policy and default risk in emerging markets. Review of Economic Dynamics, 13(2):919-933, 2010.

P D'Erasmo. Government reputation and debt repayment in emerging economies. Mimeo, University of Maryland, College Park, 2011.

P D'Erasmo and Enrique Mendoza. History remembered: Optimal sovereign default on domestic and external debt. PIER Working Paper No. 18-018, 2018.

B Doda. Optimal fiscal policy with sovereign default. Mimeo, Dept. of Economics, University of Toronto, 2007.

A Dovis, M Golosov, and A Shourideh. Political economy of sovereign debt: a theory of cycles of populism and austerity. Mimeo, Dept. of Economics, Penn State University, 2016.

J Eaton and M Gersovitz. Debt with potential repudiation: Theoretical and empirical analysis. Review of Economic Studies, 48(2):289-309, 1981.

E Farhi. Capital taxation and ownership when markets are incomplete. Journal of Political Economy, 118:908-948, 2010.

G Gelos, R Sahay, and G Sandleris. Sovereign borrowing by developing countries: What determines market access? Journal of International Economics, 83:243-254, 2011.

G Hall and T Sargent. Fiscal discriminations in three wars. Journal of Monetary Economics, 61:148-166, 2014.

G Kaminsky, C Reinhart, and C Vegh. When it rains, it pours: Procyclical capital flows and macroeconomic policies. NBER Working Papers 10780, National Bureau of Economic Research, Inc, 2004.

R Koenker. Quantile Regression. Econometric Society Monograph Series. Cambridge University Press, 2005.

R Lucas and N L Stokey. Optimal fiscal and monetary policy in an economy without capital. Journal of Monetary Economics, 12(1):55-93, 1983.

M Magill and M Quinzii. Infinite horizon incomplete markets. Econometrica, 62:853-880, 1994.

A Marcet and A Scott. Debt and deficit fluctuations and the structure of bond markets. Journal of Economic Theory, 144(2):473-501-946, 2009. 
E Mendoza and V Yue. A general equilibrium model of sovereign default and business cycles. Quaterly Journal of Economics, 127(2):889-946, 2012.

W Paczos and K Shakhnov. Sovereign debt issuance and selective default. Mimeo, Cardiff University, 2018.

U Panizza. Domestic and external public debt in developing countries. Technical Report 188, United Nations conference on trade and development, 2008.

C Reinhart and K Rogoff. The forgotten history of domestic debt. Working Paper 13946, National Bureau of Economic Research, 2008.

C Reinhart, K Rogoff, and M Savastano. Debt intolerance. Working Paper 9908, National Bureau of Economic Research, 2003.

T Sargent and F Velde. Macroeconomic features of the French revolution. Journal of Political Economy, 103:474-518, 1995.

Y Shin. Ramsey meets Bewley: Optimal government financing with incomplete markets. Mimeo, Dept. of Economics, University of Wisconsin, 2006.

C Sosa-Padilla. Sovereign defaults and banking crises. Mimeo, McMaster University, 2014.

N Stokey, R Lucas, and E Prescott. Recursive Methods in Economic Dynamics. Harvard University Press, 1989.

F Sturzenegger and J Zettelmeyer. Debt Defaults and Lessons from a Decade of Crises. The MIT press, 2006.

G Tauchen. Finite state markov-chain approximations to univariate and vector autoregressions. Economics Letters, 20:177-181, 1986.

W Zame. Efficiency and the role of default when security markets are incomplete. American Economic Review, 83(5):1142-1164, 1993. 


\section{Appendix}

\section{A Notation and Stochastic Structure of the Model}

Throughout the appendix for a generic mapping $f$ from a set $S$ to $T$, we use $s \mapsto f(s)$ or $f: S \rightarrow T$ to denote it. For the case that a mapping depends on many variables, the notation $s_{1} \mapsto f\left(s_{1}, s_{2}\right)$ is used to denote the function $f$ only as a function of $s_{1}$, keeping $s_{2}$ fixed. Also, for a generic set $A,|A|$ denotes the cardinality of $A$.

\section{B Optimization Problem for the Households}

The Lagrangian associated to the household's problem is given by

$$
\begin{aligned}
\mathcal{L}\left(\left\{c_{t}, n_{t}, b_{t+1}, \vartheta_{t}, \mu_{t}, \Psi_{t}, \kappa_{t}\right\}_{t=0}^{\infty}\right) & \equiv \sum_{t=0}^{\infty} \beta^{t} E_{\Pi\left(\cdot \mid \omega_{0}\right)}\left[\left\{c_{t}\left(\omega^{t}\right)+H\left(1-n_{t}\left(\omega^{t}\right)\right)-\left(1-\phi_{t}\left(\omega^{t}\right)\right) \psi\left(g_{t}\left(\omega^{t}\right)\right)\right.\right. \\
& -\vartheta_{t}\left(\omega^{t}\right)\left\{c_{t}\left(\omega^{t}\right)-\left(1-\tau_{t}\left(\omega^{t}\right)\right) n_{t}\left(\omega^{t}\right)+\psi\left(g_{t}\left(\omega^{t}\right)\right) p_{t}\left(\omega^{t}\right) b_{t+1}\left(\omega^{t}\right)-\psi\left(g_{t}\left(\omega^{t}\right)\right) b_{t}\left(\omega^{t-1}\right)\right\} \\
& \left.\left.+\Psi_{t}\left(\omega^{t}\right) c_{t}\left(\omega^{t}\right)+\kappa_{1 t}\left(b_{t+1}\left(\omega^{t}\right)-\underline{b}\right)+\kappa_{2 t}\left(\bar{b}-b_{t+1}\left(\omega^{t}\right)\right)\right\}\right],
\end{aligned}
$$

where $\vartheta_{t}$ and $\Psi_{t}$ are the Lagrange multipliers associated to the budget constraint and to the non-negativity restrictions for consumption, and $\kappa_{i t} i=1,2$ are the Lagrange multipliers associated to the debt limits.

Assuming interiority of the solutions, the first order conditions (FONC) are given by:

$$
\begin{aligned}
c_{t}\left(\omega^{t}\right) & : 1-\vartheta_{t}\left(\omega^{t}\right)=0 \\
n_{t}\left(\omega^{t}\right) & :-H^{\prime}\left(1-n_{t}\left(\omega^{t}\right)\right)+\vartheta_{t}\left(\omega^{t}\right)\left(1-\tau_{t}\left(\omega^{t}\right)\right)\left(\omega^{t}\right)=0 \\
b_{t+1}\left(\omega^{t}\right) & : \vartheta_{t}\left(\omega^{t}\right) p_{t}\left(\omega^{t}\right)-E_{\Pi\left(\cdot \mid \omega^{t}\right)}\left[\beta \vartheta_{t+1}\left(\omega^{t+1}\right)\left(1-d_{t+1}\left(\omega^{t+1}\right)\right)\right]=0 .
\end{aligned}
$$

where the third condition holds for $\psi\left(g_{t}\left(\omega^{t}\right)\right)=1$, and uses law of motion 2.1 for $\psi_{t+1}$.

Then, it follows that

$$
\begin{aligned}
H^{\prime}\left(\omega^{t}\right) & =\left(1-\tau_{t}\left(\omega^{t}\right)\right), \\
p_{t}\left(\omega^{t}\right) & =\beta E_{\Pi\left(\cdot \mid \omega^{t}\right)}\left[1-d_{t+1}\left(\omega^{t+1}\right)\right] .
\end{aligned}
$$

\section{Proofs for Section 3.2}

The next lemma characterizes the set of competitive equilibria as a sequence of restrictions involving FONC and budget constraints. The proof is relegated to the end of the section.

Lemma C.1. The tuple $\left(c_{t}, g_{t}, n_{t}, b_{t+1}, p_{t}\right)_{t=0}^{\infty}$ and $\boldsymbol{\sigma}$ is a competitive equilibrium iff given a $B_{0}=b_{0}$, for all $\omega^{t} \in \Omega^{t}$, for all $t$,

$$
\begin{array}{r}
c_{t}\left(\omega^{t}\right)=n_{t}\left(\omega^{t}\right)-g_{t}, \text { and } B_{t+1}\left(\omega^{t}\right)=b_{t+1}\left(\omega^{t}\right), \\
\tau_{t}\left(\omega^{t}\right)=\left(1-H^{\prime}\left(1-n_{t}\left(\omega^{t}\right)\right)\right), \\
Z_{t}\left(\omega^{t}\right)+\phi_{t}\left(\omega^{t}\right)\left\{p_{t}\left(\omega^{t}\right) B_{t+1}\left(\omega^{t}\right)-B_{t}\left(\omega^{t}\right)\right\} \geq 0,
\end{array}
$$


where

$$
p_{t}\left(\omega^{t}\right)=\beta E_{\Pi\left(\cdot \mid \omega^{t}\right)}\left[1-d_{t+1}\left(\omega^{t+1}\right)\right],
$$

if $\phi_{t}\left(\omega^{t}\right)=1$, and if $\phi_{t}\left(\omega^{t}\right)=0, B_{t+1}\left(\omega^{t}\right)=B_{t}\left(\omega^{t-1}\right)$.

Proof of Proposition 3.1. We now show the " $\Rightarrow$ " direction. Consider an outcome path $\left(d_{t}, B_{t+1}, n_{t}\right)_{t=0}^{\infty}$ that is consistent. This means by lemma C.1 that the tuple $\left(c_{t}, g_{t}, n_{t}, b_{t+1}, p_{t}\right)_{t=0}^{\infty}$ and $\boldsymbol{\sigma}$ is a competitive equilibrium iff given a $B_{0}=b_{0}$, for all $\omega^{t} \in \Omega^{t}$, for all $t$, equations C.22, C.23, C.24 and C.25 hold. Equations C.23 and C.25 correspond to equations 3.4 and 3.5. Equations C.23-C.25 imply condition 3.7.

We now show the " $\Leftarrow$ " direction. Suppose now that the outcome path satisfies, for all $\omega^{t} \in \Omega^{t}$, the following equations: 2.2, 3.4, 3.5, and 3.7. By using $B_{t+1}\left(\omega^{t}\right)=b_{t+1}\left(\omega^{t}\right)$, equations 3.4, 3.5 and the feasibility condition, we can enlarge the outcome path by $\left(c_{t}, p_{t}, b_{t+1}, \tau_{t}, g_{t}\right)_{t=0}^{\infty}$. Clearly, restrictions C.22, C.23 and C.25 hold. By replacing equations 3.4 and 3.5 on 3.7, it is easy to see that equation C.23 holds too.

\section{C.1 Proofs of Supplementary Lemmas}

For the proof of Lemma C.1 we need the following lemma (the proof is relegated to the end of the section).

Lemma C.2. Under assumption 2.2, first order conditions 3.4 and 3.5 are also sufficient.

Proof of Lemma C.1. Take $\boldsymbol{\sigma}$ and $\left(c_{t}, g_{t}, n_{t}, b_{t+1}\right)_{t=0}^{\infty}$, and a price schedule $\left(p_{t}\right)_{t}$ that satisfy the equations. It is easy to see that feasibility and market clearing holds (conditions 3 and 4). Also, by lemma C.2 optimality of the households is also satisfied.

To check attainability of the government policy (condition 2), observe that equations C.22 - C.24 imply for all $\omega^{t} \in \Omega^{t}$,

$$
g_{t}\left(\omega^{t}\right)+\phi_{t}\left(\omega^{t}\right)\left\{B_{t}\left(\omega^{t-1}\right)-p_{t}\left(\omega^{t}\right) B_{t+1}\left(\omega^{t}\right)\right\} \leq \tau_{t}\left(\omega^{t}\right) n_{t}\left(\omega^{t}\right) .
$$

Finally, we check optimality of the households. We first check that the sequences satisfy the budget constraint. Observe that by equations C.22 - C.24

$$
-c_{t}\left(\omega^{t}\right)+n_{t}\left(\omega^{t}\right)+\phi_{t}\left(\omega^{t}\right)\left\{B_{t}\left(\omega^{t-1}\right)-p_{t}\left(\omega^{t}\right) B_{t+1}\left(\omega^{t}\right)\right\} \leq \tau_{t}\left(\omega^{t}\right) n_{t}\left(\omega^{t}\right) .
$$

If $\phi_{t}\left(\omega^{t}\right)=1$, then equation C.24 implies that $b_{t+1}\left(\omega^{t}\right)=B_{t+1}\left(\omega^{t}\right)$ for all $t$ (and for $b_{0}$ we assume it is equal to $\left.B_{0}\right)$ and thus

$$
-c_{t}\left(\omega^{t}\right)+n_{t}\left(\omega^{t}\right)+b_{t}\left(\omega^{t-1}\right)-p_{t}\left(\omega^{t}\right) b_{t+1}\left(\omega^{t}\right) \leq \tau_{t}\left(\omega^{t}\right) n_{t}\left(\omega^{t}\right) .
$$

This coincides with the budget constraint of the household.

If $d_{t}\left(\omega^{t}\right)=1$, equations C.22 and C.24 imply that $b_{t}\left(\omega^{t-1}\right)=b_{t+1}\left(\omega^{t}\right)=0$ for all $t$, so $-c_{t}\left(\omega^{t}\right)+$ $n_{t}\left(\omega^{t}\right)=\tau_{t}\left(\omega^{t}\right) n_{t}\left(\omega^{t}\right)$, which is the budget constraint of the household.

Take $\boldsymbol{\sigma}$ and $\left(c_{t}, g_{t}, n_{t}, b_{t+1}, p_{t}\right)_{t=0}^{\infty}$ being a competitive equilibrium. Then it is easy to see that it satisfies the equations.

Proof of Lemma C.2. Under assumption 2.2 the objective function of the household optimization problem is strictly concave. The budget constraints and debt constraint form a convex set of constraints. Thus, if the transversality condition holds, the FONC are sufficient; this follows from a simple adaptation of the results in Stokey et al. [1989] Ch. 4.5.

In order to verify the transversality condition, it suffices to show that for any $\zeta_{t}\left(\omega^{t}\right)$ such that $b_{t}\left(\omega^{t}\right)+\zeta_{t}\left(\omega^{t}\right) \in \mathbb{B}$,

$$
\lim _{T \rightarrow \infty} \beta^{T} E_{\Pi}\left[\varrho_{T}\left(\omega^{T}\right) \zeta_{T}\left(\omega^{T}\right)\right]=0,
$$

which follows from Magill and Quinzii [1994] Theorem 5.2 as debt is constrained by assumption. 


\section{Proofs for Section 4}

The next lemma characterizes the government surplus function.

Lemma D.1. Let $(n, g) \mapsto z(n, g)=\left(1-H^{\prime}(1-n)\right) n-g$. Then:

1. $\arg \max _{n \in[0,1]}\{n-g+H(1-n): z(n, g)=0\}$ exists and is unique.

2. Let $\bar{n}(g)=\arg \max _{n \in[0,1]} z(n, g)$. Then, $n \mapsto z(n, g)$ is decreasing and strictly concave for all $n \in[\bar{n}(g), 1]$

Proof of Lemma D.1. (1) Let $u(n-g, 1-n) \equiv n-g+H(1-n)$. Under assumption $2.2, n \mapsto u^{\prime}(n-g, 1-$ $n)=\frac{\partial n-g+H(1-n)}{\partial n}=1-H^{\prime}(1-n)=1-(1-\tau)$ and since $\tau \in[0,1]$ it implies that $u^{\prime}(n-g, 1-n)>0$. Also, $n \mapsto u(n-g, 1-n)$ is continuous. Moreover, let $\{n: z(n, g)=0\}=\left\{n:\left(1-H^{\prime}(1-n)\right) n-g=0\right\}$. Under assumption 2.2, $H^{\prime}(\cdot)$ is continuous, and thus this set is closed (and bounded). Therefore it is compact. By the theorem of the maximum $\arg \max _{n \in[0,1]}\{u(n-g, 1-n): z(n, g)=0\}$ exists. Uniqueness follows from the fact that $n \mapsto u(n-g, 1-n)$ is increasing.

(2) First observe that $n \mapsto z(n, g)=\left(1-H^{\prime}(1-n)\right) n-g$ is continuous and thus $\bar{n}(g)$ exists for all $g \in \mathbb{G}\left(\mathbb{G}\right.$ is such that for all $\left.g \in \mathbb{G}, \max _{n \in[0,1]} z(n, g) \geq g\right)$. Observe that $n \mapsto z^{\prime}(n, g)=$ $\left(1-H^{\prime}(1-n)\right)+H^{\prime \prime}(1-n) n$ and $n \mapsto z^{\prime \prime}(n, g)=2 H^{\prime \prime}(1-n)-H^{\prime \prime \prime}(1-n) n$. By assumption 2.2, $z^{\prime \prime}(n, g)<0$ and thus is strictly concave. We now show that $z$ is decreasing. If $\bar{n}(g)=1$ then the statement is vacuous, so consider $\bar{n}(g)<1$. Since $\bar{n}(g)$ is the "argmax", $z^{\prime}(\bar{n}(g), g) \leq 0$. Since $z$ is strictly concave, $z^{\prime}$ is a decreasing, hence $z^{\prime}(n, g)<z^{\prime}(\bar{n}(g), g) \leq 0$ for all $n>\bar{n}(g)$, and the result follows.

Lemma D.2. There exists $\bar{\lambda}$ such that for all $\lambda \in[0, \bar{\lambda}]$, the following holds: for all $(g, B)$ such that $B>0$ and $\mathbf{d}^{*}(g, B)=1, \mathcal{P}^{*}\left(g, B^{\prime}\right) B^{\prime} \leq B$ for all $B^{\prime} \in \mathbb{B}$.

Proof of Lemma D.2. Suppose not. That is, there exists a $(g, B)$ with $B>0$ such that $\mathbf{d}^{*}(g, B)=1$ but there exists a $B^{\prime}$ such that $\mathcal{P}^{*}\left(g, B^{\prime}\right) B^{\prime}>B$.

First observe that for any $\left(g, B, B^{\prime}\right)$ such that $\mathcal{P}^{*}\left(g, B^{\prime}\right) B^{\prime}>B$,

$$
z\left(\mathbf{n}\left(g, B, B^{\prime}\right), g\right)<z\left(\mathbf{n}_{0}^{*}(g), g\right)
$$

where $\mathbf{n}\left(g, B, B^{\prime}\right)$ is the level of labor that solves $z(n, g)+\mathcal{P}^{*}\left(g, B^{\prime}\right) B^{\prime}=B$. Since $n \mapsto z(n, g)$ is non-increasing in the relevant domain (see lemma D.1(2)), it follows that $\mathbf{n}\left(g, B, B^{\prime}\right)>\mathbf{n}_{0}^{*}(g)$, thereby implying that the per-period payoff is greater under no default, i.e.,

$$
r\left(\mathbf{n}\left(g, B, B^{\prime}\right)\right)-g-\left\{r\left(\mathbf{n}_{0}^{*}(g)\right)-g\right\}>0
$$

where $n \mapsto r(n)=n+H(1-n)$ is increasing by our assumptions. Let $U \equiv\left\{\left(g, B, B^{\prime}\right) \in \mathbb{G} \times \mathbb{B}^{2}:\right.$ equation D.26 holds $\}$. Under our assumptions $|U|<\infty$, so there exists a $\epsilon^{\prime}>0$ such that $r\left(\mathbf{n}\left(g, B, B^{\prime}\right)\right)-g-$ $\left\{r\left(\mathbf{n}_{0}^{*}(g)\right)-g\right\} \geq \epsilon^{\prime}$ for all $\left(g, B, B^{\prime}\right) \in U$. Consider any $\lambda \in\left[0, \lambda\left(0.5 \epsilon^{\prime}\right)\right]$ where $\epsilon \mapsto \lambda(\epsilon)$ is such that

$$
\lambda(\epsilon)\left|\int_{\mathbb{G}} V_{1}^{*}\left(g^{\prime}, B^{\prime}\right) \pi_{\mathbb{G}}\left(d g^{\prime} \mid g\right)\right| \leq \epsilon
$$

it is easy to see that such $\lambda$ exists as $V_{1}^{*}(\cdot, \cdot)$ is bounded from above. By our hypothesis, there exists a $\left(g, B, B^{\prime}\right)$ with $B>0$ such that $\mathbf{d}^{*}(g, B)=1$ and $\mathcal{P}^{*}\left(g, B^{\prime}\right) B^{\prime}>B$. And thus $\left(g, B, B^{\prime}\right) \in U$. By our choice of $\lambda$,

$$
\int_{\mathbb{G}} V_{0}^{*}\left(g^{\prime}, B^{\prime}\right) \pi_{\mathbb{G}}\left(d g^{\prime} \mid g\right)+0.5 \epsilon^{\prime} \geq \int_{\mathbb{G}}\left\{\lambda V_{1}^{*}\left(g^{\prime}, 0\right)+(1-\lambda) V_{0}^{*}\left(g^{\prime}, B^{\prime}\right)\right\} \pi_{\mathbb{G}}\left(d g^{\prime} \mid g\right) .
$$


By definition of $\epsilon^{\prime}$ and the fact that $\left(g, B, B^{\prime}\right) \in U$, it follows that

$$
\begin{aligned}
& r\left(\mathbf{n}\left(g, B, B^{\prime}\right)\right)-g+\beta \int_{\mathbb{G}} \max \left\{V_{1}^{*}\left(g^{\prime}, B^{\prime}\right), V_{0}^{*}\left(g^{\prime}, B^{\prime}\right)\right\} \pi_{\mathbb{G}}\left(d g^{\prime} \mid g\right) \\
> & r\left(\mathbf{n}_{0}^{*}(g)\right)-g+0.5 \epsilon^{\prime}+\beta \int_{\mathbb{G}} V_{0}^{*}\left(g^{\prime}, B^{\prime}\right) \pi_{\mathbb{G}}\left(d g^{\prime} \mid g\right) \\
\geq & r\left(\mathbf{n}_{0}^{*}(g)\right)-g+\beta\left\{\int_{\mathbb{G}} V_{0}^{*}\left(g^{\prime}, B^{\prime}\right) \pi_{\mathbb{G}}\left(d g^{\prime} \mid g\right)+0.5 \epsilon^{\prime}\right\} \\
\geq & V_{0}^{*}(g, B) .
\end{aligned}
$$

Since $V_{1}^{*}(g, B)$ is larger or equal than the LHS, we conclude that for $(g, B)$ the government decides not to default, but this is a contradiction to the fact that $\mathbf{d}^{*}(g, B)=1$.

\section{D.1 Derivation of Equation 5.14}

In this setting, to default or not, boils down to choosing a $T$ (contingent on $\omega^{\infty}$ ) such that for all $t<T\left(\omega^{\infty}\right)$ there is no default and for $t \geq T\left(\omega^{\infty}\right)$ there is financial autarky. Recall that under our assumptions $u(c, l)=c+H(l)$ and $g_{t} \sim i i d \pi_{\mathbb{G}}$, also $\pi_{\mathbb{G}}$ has a density with respect to Lebesgue, which we denote as $f_{\pi_{\mathrm{G}}}$.

For any $\omega^{t} \in \Omega^{t}$ and $t \leq T\left(\omega^{\infty}\right)$,

$$
\begin{aligned}
V_{1}^{*}\left(g_{t}, B_{t}\left(\omega^{t-1}\right)\right)= & \max _{\left(n, B^{\prime}\right) \in \Gamma\left(g_{t}, B_{t}\left(\omega^{t-1}\right), 1\right)} n-g+H(1-n)+\beta \int_{\left\{g^{\prime}: g^{\prime} \leq \bar{g}\left(B^{\prime}\right)\right\}}\left\{V_{1}^{*}\left(g^{\prime}, B^{\prime}\right)-V_{0}^{*}\left(g^{\prime}\right)\right\} \pi_{\mathbb{G}}\left(d g^{\prime}\right) \\
& +\beta \int V_{0}^{*}\left(g^{\prime}\right) \pi_{\mathbb{G}}\left(d g^{\prime}\right)
\end{aligned}
$$

and let $\nu_{t}\left(\omega^{t}\right)$ is the Lagrange multiplier of the restriction, $z\left(1, n, g_{t}\right)+\mathcal{P}^{*}\left(B^{\prime}\right) B^{\prime}-B_{t}\left(\omega^{t-1}\right) \geq 0$. By assumption, the solution of $B^{\prime}$ is in the interior. So the optimal choice $\left(\left(n_{t}\left(\omega^{t}\right)\right)_{t=0}^{\infty},\left(B_{t+1}\left(\omega^{t}\right)\right)_{t=0}^{\infty}\right)$ satisfy

$$
1-H^{\prime}\left(1-n_{t}\left(\omega^{t}\right)\right)+\nu_{t}\left(\omega^{t}\right)\left(\frac{d z\left(1, n_{t}\left(\omega^{t}\right), g_{t}\right)}{d n}\right)=0
$$

or equivalently

$$
\nu_{t}\left(\omega^{t}\right) \equiv \boldsymbol{\nu}\left(n_{t}\left(\omega^{t}\right)\right)=-\frac{1-H^{\prime}\left(1-n_{t}\left(\omega^{t}\right)\right)}{1-H^{\prime}\left(1-n_{t}\left(\omega^{t}\right)\right)+H^{\prime \prime}\left(1-n_{t}\left(\omega^{t}\right)\right) n_{t}\left(\omega^{t}\right)}
$$

and

$$
\begin{aligned}
& \nu_{t}\left(\omega^{t}\right)\left\{\mathcal{P}^{*}\left(B_{t+1}\left(\omega^{t}\right)\right)+\frac{d \mathcal{P}^{*}\left(B_{t+1}\left(\omega^{t}\right)\right)}{d B_{t+1}} B_{t+1}\left(\omega^{t}\right)\right\} \\
= & \beta \frac{d \int_{\left\{g^{\prime}: g^{\prime} \leq \bar{g}\left(B_{t+1}\left(\omega^{t}\right)\right)\right\}}\left\{V_{1}^{*}\left(g^{\prime}, B_{t+1}\left(\omega^{t}\right)\right)-V_{0}^{*}\left(g^{\prime}\right)\right\} \pi_{\mathbb{G}}\left(d g^{\prime}\right)}{d B_{t+1}} \\
= & \beta \int_{\left\{g^{\prime}: g^{\prime} \leq \bar{g}\left(B_{t+1}\left(\omega^{t}\right)\right)\right\}} \frac{d V_{1}^{*}\left(g^{\prime}, B_{t+1}\left(\omega^{t}\right)\right)}{d B_{t+1}} \pi_{\mathbb{G}}\left(d g^{\prime}\right) \\
& +\beta\left\{V_{1}^{*}\left(\bar{g}\left(B_{t+1}\left(\omega^{t}\right)\right), B_{t+1}\left(\omega^{t}\right)\right)-V_{0}^{*}\left(\bar{g}\left(B_{t+1}\left(\omega^{t}\right)\right)\right)\right\} f_{\pi_{\mathbb{G}}}\left(\bar{g}\left(B_{t+1}\left(\omega^{t}\right)\right)\right) \frac{d \bar{g}\left(B_{t+1}\left(\omega^{t}\right)\right)}{d B_{t+1}} .
\end{aligned}
$$

Since $V_{1}^{*}\left(\bar{g}\left(B_{t+1}\left(\omega^{t}\right)\right), B_{t+1}\left(\omega^{t}\right)\right)-V_{0}^{*}\left(\bar{g}\left(B_{t+1}\left(\omega^{t}\right)\right)\right)=0$, the last term in the RHS is naught. Also, $\frac{d V_{1}^{*}\left(g_{t}, B_{t}\left(\omega^{t-1}\right)\right)}{d B_{t}}=\nu_{t}\left(\omega^{t}\right)$ and thus

$$
\nu_{t}\left(\omega^{t}\right)\left\{\mathcal{P}^{*}\left(B_{t+1}\left(\omega^{t}\right)\right)+\frac{d \mathcal{P}^{*}\left(B_{t+1}\left(\omega^{t}\right)\right)}{d B_{t+1}} B_{t+1}\left(\omega^{t}\right)\right\}=\beta \int_{\left\{g^{\prime}: g^{\prime} \leq \bar{g}\left(B_{t+1}\left(\omega^{t}\right)\right)\right\}} \nu_{t+1}\left(\omega^{t}, g^{\prime}\right) \pi_{\mathbb{G}}\left(d g^{\prime}\right)
$$


We now show that $\boldsymbol{\nu}$ is decreasing. For this it is easier to first establish that $\boldsymbol{\nu}^{-} \equiv 1 / \boldsymbol{\nu}$ is increasing. Observe that

$$
\boldsymbol{\nu}^{-}(n)=-1-\frac{H^{\prime \prime}(1-n) n}{1-H^{\prime}(1-n)}
$$

and thus

$$
\frac{d \boldsymbol{\nu}^{-}(n)}{d n}=-\frac{-H^{\prime \prime \prime}(1-n) n+H^{\prime \prime}(1-n)}{1-H^{\prime}(1-n)}-\frac{\left(H^{\prime \prime}(1-n)\right)^{2} n}{\left(1-H^{\prime}(1-n)\right)^{2}}
$$

Since $-H^{\prime \prime \prime}(1-n) n+H^{\prime \prime}(1-n)<0$ by assumption and $1-H^{\prime}(1-n)=\tau>0$, then the first term in the RHS is negative; the second term in the RHS is also negative. Hence $\boldsymbol{\nu}^{-}$is increasing, which readily implies that $\boldsymbol{\nu}$ is decreasing.

\section{D.2 Proof of Equivalence for Commitment Technologies to Default}

We show next that in the economy with one-period commitment to default the equilibrium outcome is the same that if we assume full commitment, that is, if the government can commit to its default strategy for all future periods. The former economy is presented in subsection 6.1. The government's optimization problem there is given by Bellman equation 6.17.

Here, we analyze the sequential problem for the government. Let us assume for simplicity that the default decision has a threshold specification, i.e. $\mathbf{d}_{t}\left(\omega^{t-1}, s_{t}\right)=\mathbf{1}_{\left\{g_{t}: g_{t} \geq \bar{g}_{t}\left(\omega^{t-1}, s_{t}\right)\right\}}\left(g_{t}\right)$. Taking FOCs with respect to $B_{t+1}\left(\omega^{t}\right), n_{t}\left(\omega^{t}\right)$, and $\mathbf{d}_{t+1}\left(\omega^{t}, s_{t+1}\right)$ we obtain

$$
\begin{aligned}
p_{t}\left(\omega^{t}\right) \nu_{t}\left(\omega^{t}\right) & =\beta E_{t}\left[1-d_{t+1}\left(\omega^{t}, s_{t+1}\right)\right] \nu_{t+1}\left(\omega^{t+1}\right) \\
\nu_{t}\left(\omega^{t}\right) & =-\frac{1-H^{\prime}\left(1-n_{t}\left(\omega^{t}\right)\right)}{1-H^{\prime}\left(1-n_{t}\left(\omega^{t}\right)\right)+H^{\prime \prime}\left(1-n_{t}\left(\omega^{t}\right)\right) n_{t}\left(\omega^{t}\right)} \\
-\nu_{t}\left(\omega^{t}\right) B_{t+1}\left(\omega^{t}\right) & =E_{t}\left[V_{1, t+1}^{*}\left(\omega^{t}, \bar{g}_{t+1}, s_{t+1}\right)-V_{0, t+1}^{*}\left(\omega^{t}, \bar{g}_{t+1}, s_{t+1}\right)\right],
\end{aligned}
$$

where $\nu_{t}\left(\omega^{t}\right)$ is the Lagrange multiplier associated to the implementability constraint after history $\omega^{t}$, and we have used Leibniz integral rule for condition D.32.

Substituting $p_{t}\left(\omega^{t}\right)$ by its equilibrium expression 3.5 in equation D.30 yields

$$
\nu_{t}\left(\omega^{t}\right)=\frac{E_{t}\left[1-d_{t+1}\left(\omega^{t}, s_{t+1}\right) \nu_{t+1}\left(\omega^{t+1}\right)\right]}{E_{t}\left[1-d_{t+1}\left(\omega^{t}, s_{t+1}\right)\right]},
$$

Equations D.31-D.33 for all histories $\left(\omega^{t}, s_{t+1}\right)$ together with the utility recursions for $V_{1, t}^{*}\left(\omega^{t}\right)$ and $V_{0, t}^{*}\left(\omega^{t}\right)$ fully characterize the equilibrium outcome in this economy when the government sets the default decision one period in advance. With one-period bonds, it is straightforward to see that if all decisions are made once and for all at time 0 the equilibrium conditions are identical. Hence, it follows that in our setup having one-period-ahead commitment for default is isomorphic to having full commitment.

\section{D.3 Examples in a Two-Period Model}

In our calibrated model, we find that giving the government the option to default limits substantially its ability to smooth taxes. This, however, is not always true for any arbitrary economy. To show this, we present next two examples in a simple two-period model with and without default. 
Consider an economy with two periods such that in the first period $g=g_{1}$ for $g_{1}$ sufficiently high, and in the second period $g=g_{L}$ with probability $\pi$, and $g=g_{H}$ with probability $(1-\pi)$. The government is allowed to borrow from households through a non-state-contingent bond and thereby smooth taxes between the two periods. In the default model, the government may choose not to repay the debt in the second period, in which case it receives a per-period payoff of $\phi$.

Example 1. Let $g_{H}$ be equal to the maximal tax revenues that the government can collect. In that case, if $g=g_{H}$ the government would not be able to pay back any positive amount of bonds. Hence, if the government cannot default, it would issue no bonds in the first period resulting in a no-borrowing equilibrium. In contrast, if the option to default is available, it can happen that the government decides to repay only if $g=g_{L}$. In that case, through some borrowing at a bond price $\beta \pi$, the government can achieve some tax smoothing. Therefore, in this first example, the benefits of the option of default coming from completing the markets prevail on lowering the tax volatility.

Example 2. By setting $g_{L}$ and $g_{H}$ sufficiently close to each other, the probability $\pi$ sufficiently low and $\phi$ for default to be optimal only if $g=g_{H}$, it is easy to see how a low bond price in the first period coupled with a borrowing cap that ensures repayment is optimal if $g=g_{L}$ results in more limited smoothing of taxes between the first period and the second period for $g=g_{L}$ when the government can default. In this second example, instead, the option to default (in a Markovian fashion) does not help reducing the tax variability.

For instance, as a numerical illustration, assume the same functional forms and parametrization for households' preferences as in the baseline calibration, with the exception of the utility value of defaulting which we set $\phi=0.465$. Also, let $g_{L}=0.2$. For the first example, set $g_{H}=0.4675$. The tax vector $\left(\tau_{1}, \tau_{L}\right)$ is equal to $(0.5,0.23)$ in the risk-free debt model and $(0.497,0.254)$ when the government is given the option to default. The government here decides to repay only if $g=g_{L}$, which is the only state in which it can make some resources available for bond repayments. As bond prices remain positive, it can borrow from households to somewhat reduce the tax variability between the first period and the second one when it repays relative to the no-trading allocation. In the second example, we assume $g_{H}=0.3$. Let the tax rates in the first period and second period with $g=g_{L}$ be denoted by $\tau_{1}$ and $\tau_{L}$, respectively. In the risk-free debt economy, $\left(\tau_{1}, \tau_{L}\right)=(0.422,0.296)$, while in the default model the counterpart is $(0.497,0.253)$. In the latter model, the government again chooses to repay only if $g=g_{L}$. In the risk-free debt model, however, the government can now pay back some positive amount of bonds in all states. More and cheaper borrowing allows for more tax smoothing relative to the economy with the option to default. 


\section{Supplementary Online Material}

\section{E Stylized Facts: Emerging vs. Industrialized Economies}

Throughout the paper, we mention that our theoretical model is capable of replicating qualitatively several stylized facts observed for a wide range of economies. In this section, we present these stylized facts regarding the domestic government debt-to-output ratio and central government revenue-to-output ratio of several countries: industrialized economies (IND), emerging economies (EME) and a subset of these: Latin American (LAC). ${ }^{36}$

In our dataset (described in section F), no default event is observed for IND, whereas EME/LAC (LAC in particular) do exhibit several defaults. Thus, we take the former group as a proxy for economies with access to risk-free debt and the latter group as a proxy for economies without commitment to repay. It is worth to point out however that we are not presuming that IND economies are a type of economy that would never never default. In turn, we are just using the fact that in our dataset IND economies do not show default events, to use them as a proxy for the type of economy modeled in AMSS, that is, one with risk-free government debt.

Several stylized facts that stand out in our dataset. First, in EME/LAC economies default is more likely than in IND economies and within the former group, the default risk is much higher for highly indebted economies. Second, EME and LAC economies exhibit tighter debt ceilings than IND, as also reported by Reinhart et al. [2003]. Third, economies with higher default risk tend to exhibit more volatile tax revenues than those with low default risk, and this fact is particularly notable for the group of EME/LAC economies. Bauducco and Caprioli [2014] documents a similar finding.

As shown in section 5, our theory predicts that endogenous borrowing limits are more active for a high level of indebtedness. That is, when the government debt is high relative to output, the probability of default next period is higher, thus implying tighter borrowing limits and higher bond spreads. As the government's ability to smooth its needs for funds using debt is hindered, the volatility of taxes turns out to be higher. But when debt is low, default is an unlikely event, thereby implying less stringent borrowing limits, lower spreads and therefore lower volatility in taxes. Hence, implications in the upper tail of the domestic debt-to-output ratio distribution can be different from those in the "central part" of it. Therefore, the mean and even the variance of the distribution may not be too informative, as they are affected by the central part of the distribution. Quantiles are better suited for recovering the information in the tails of the distribution. ${ }^{37}$

Figure E.8 plots the percentiles of the domestic government debt-to-output ratio and of a measure of default risk for three groups: IND (black triangle), EME (blue square) and LAC (red circle). ${ }^{38}$ The Xaxis plots the time series averages of domestic government debt-to-output ratio, and the Y-axis plots the

\footnotetext{
${ }^{36}$ For government revenue-to-output ratios, we used the data from Kaminsky et al. [2004], and for the domestic government debt-to-output ratios, we used the data from Panizza [2008]. We thank Ugo Panizza and Carmen Reinhart for kindly sharing their datasets with us. See appendix F for a detailed description of the data.

${ }^{37}$ We refer the reader to Koenker [2005] for a thorough treatment of quantiles and quantile-based econometric models.

${ }^{38}$ This type of graph is not the conventional QQplot as the axis have the value of the random variable which achieves a certain quantile and not the quantile itself. For our purposes, this representation is more convenient.
} 


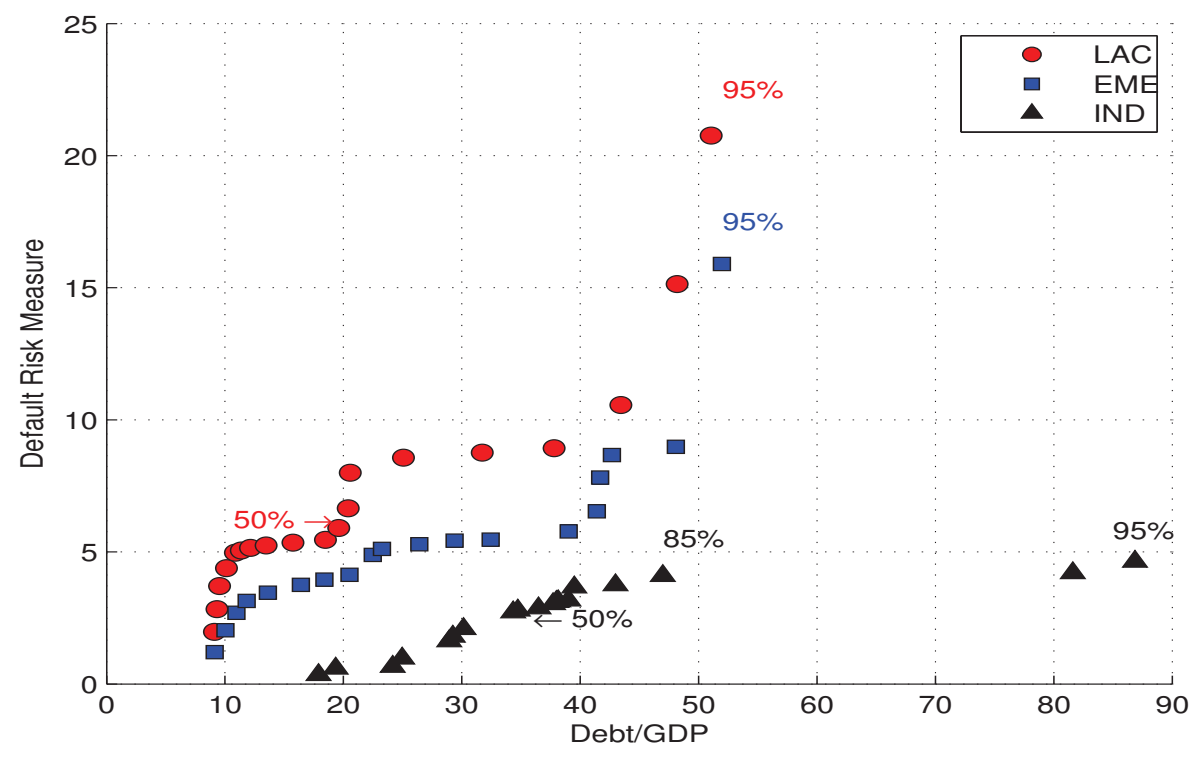

Figure E.8: The percentiles of the domestic government debt-to-output ratio and of a measure of default risk for three groups: IND (black triangle), EME (blue square) and LAC (red circle)

values of the measure of default risk. ${ }^{39}$ For each group, the last point on the right corresponds to the 95 percentile, the second to last to the 90 percentile and so on; these are comparable between groups as all of them represent a percentile of the corresponding distribution. EME and LAC have lower domestic debtto-output ratio levels than IND; in fact the domestic debt-to-output ratio value of around 50 percent that pertains to the 95 percentile for EME and LAC, corresponds roughly to only the 85 percentile for IND. Thus, economies that are prone to default (EME and LAC) exhibit tighter debt ceilings than economies that do not default (in this dataset, represented by IND).

Figure E.8 also shows that for the IND group, the default risk measure is low and roughly constant for different levels of debt-to-output ratios. On the other hand, the default risk measure for the EME group is not only higher, but increases substantially for high levels of indebtness. We consider this as evidence that for EME economies higher default risk is more prevalent for high levels of debt-to-output ratios.

Table E.4(A) compares the measure of default risk between IND and EME for low and high debt-tooutput ratio levels. That is, for both groups (IND and EME) we select economies with debt-to-output ratio below the 25 th percentile (low debt-to-output) for which we compute the average risk measure. We proceed analogously with those economies with debt-to-output ratio above the 75 th percentile (high

\footnotetext{
${ }^{39}$ The measure of default risk is constructed as the spread using the EMBI+ real index from J.P. Morgan for countries for which it is available and using the 3-7 year real government bond yield for the rest, minus the return of a US Treasury bond of similar maturity. Although bond returns are not entirely driven by default risk but also respond to other factors related to risk appetite, uncertainty and liquidity, for our purpose they constitute a valid conventional proxy of default risk. Furthermore, our spreads are an imperfect measure of default risk for domestic debt since EMBI+ considers mainly foreign debt. However, it is still informative since domestic default are positively correlated with defaults on sovereign debt, at least for the period from 1950's onwards. See figure 10 in Reinhart and Rogoff [2008].
} 
Table E.4: (A) Measure of default risk (\%) for EME and IND groups for different levels of debt-to-output ratio (\%); (B) standard deviation of central government revenue over GDP (\%) for EME and IND groups for different levels of default risk.

\begin{tabular}{|c|c|c|c|c|c|}
\hline \multicolumn{3}{|c|}{ (A) } & \multicolumn{3}{|c|}{ (B) } \\
\hline Debt/GDP & EME & IND & Default Risk & EME & IND \\
\hline 25 & 5.4 & 2.0 & 25 & 0.9 & 1.4 \\
\hline 75 & 10.7 & 2.9 & 75 & 2.5 & 1.7 \\
\hline
\end{tabular}

debt-to-output). For the case of low debt-to-ouput levels, the EME group presents higher (approximately twice as high) default risk than the IND group. For high debt-to-output ratio economies, however, this difference is quadrupled. Thus, economies that are prone to default (EME and LAC) exhibit higher default risk than economies that do not default (in this dataset, represented by IND), and, moreover, the default risk is much higher for economies in the former group that have high levels of debt-to-output ratio.

Table E.4(B) compares the standard deviation of the central government revenue-to-output ratio between IND and EME for low and high default risk levels. It indicates that for IND there is little variation of the volatility across low and high levels of default risk. For EME, however, the standard deviation of the central government revenue-to-output ratio is dramatically higher for economies with high default risk. ${ }^{40}$. It is worth pointing out that all the EME with high default risk levels defaulted at least once during our sample period. Thus, economies with higher default risk exhibit more volatile tax revenues than economies with low default risk. This is particularly notable for the group of EME/LAC economies.

These stylized facts establish a link between (a) default risk/default events, (b) debt ceilings and (c) volatility of tax revenues. In particular, the evidence suggests that economies that show higher default risk, also exhibit lower debt ceilings and more volatile tax revenues. The theory behind our model helps shed light upon the forces driving these facts. ${ }^{41}$

\section{F Description of the Data}

In this section we describe how we constructed the figures presented in section E.

The industrialized economies group consists of AUSTRALIA (1990-1999), AUSTRIA (1990-1999), BELGIUM (1990-2001), CANADA (1990-2003), DENMARK (1990-2003), FINLAND (1994-1998), FRANCE (1990-2003), GERMANY (1990-1998), GREECE (1990-2001), IRELAND (1995-2003), ITALY (19902003), JAPAN (1990-1993), NETHERLANDS (1990-2001), NEW ZEALAND (1990-2003), NORWAY (1990-2003), PORTUGAL (1990-2001), SPAIN (1990-2003), SWEDEN (1990-2003), SWITZERLAND (1990-2003), UNITED KINGDOM (1990-2003) and UNITED STATES (1990-2003).

The emerging economies group consists of ARGENTINA ${ }^{1}$ (1998-2003), BOLIVIA ${ }^{1}$ (2001-2003), BRAZIL ${ }^{1}$ (1997-2003), CHILE ${ }^{1}$ (1993-2003), COLOMBIA ${ }^{1}$ (1999-2003), ECUADOR ${ }^{1}$ (1998-2003), EL SALVADOR$^{1}$ (2000-2003), HONDURAS ${ }^{1}$ (1990-2003), JAMAICA ${ }^{1}$ (1990-2003), MEXICO¹ (1990-2003),

\footnotetext{
${ }^{40}$ We looked also at the inflation tax as a proxy for tax policy; results are qualitatively the same.

${ }^{41}$ It is important to note that we are not arguing any type of causality; we are just illustrating co-movements. In fact, in the model below all three features are endogenous outcomes of equilibrium.
} 
PANAMA ${ }^{1}$ (1997-2003), PERU ${ }^{1}$ (1998-2003), VENEZUELA ${ }^{1}$ (1997-2003), ALBANIA (1995-2003), BULGARIA (1991-2003), CYPRUS (1990-2003), CZECH REPUBLIC (1993-2003), HUNGARY (1991-2003), LATVIA (1990-2003), POLAND (1990-2003), RUSSIA (1993-2003), TURKEY (1998-2003), ALGERIA (1990-2003), CHINA (1997-2003), EGYPT (1993-2003), JORDAN (1990-2003), KOREA (1990-2003), MALAYSIA (1990-2003), MAURITIUS (1990-2003), MOROCCO (1997-2003), PAKISTAN (1990-2003), PHILIPPINES (1997-2003), SOUTH AFRICA (1990-2003), THAILAND (1999-2003) and TUNISIA (1994-2003). The LAC group is conformed by the countries with "1".

For section E we constructed the data as follows. First, for each country, we computed time average, or time standard deviations or any quantity of interest (in parenthesis is the number of observations use to construct these). Second, once we computed these averages, we group the countries in IND, EME and LAC. We do this procedure for (a) central government domestic debt (as \% of output) ; (b) central government expenditure (as \% of output) ; (c) central government revenue (as \% of output), and (d) Real Risk Measure. The data for (a) is taken from Panizza [2008] ; the data for (b-c) is taken from Kaminsky et al. [2004] ; finally the data for (d) is taken from www.globalfinancialdata.com.

For Greece and Portugal we use central government public debt because central government domestic debt was not available. For Sweden, Ecuador and Thailand we use general government expenditure because central government expenditure was not available. For Albania, Bulgaria, Cyprus, Czech Rep., Hungary, Latvia, Poland and Russia no measure of government expenditure was available and thus were excluded from the sample for the calculations of this variable. The same caveats apply to the central government revenue sample. For Argentina, Brazil, Colombia, Ecuador, Egypt, Mexico, Morocco, Panama, Peru, Philippines, Poland, Russia, Turkey and Venezuela we used the real EMBI+ as a measure of real risk. For the rest of the countries we used differences in government note yields of 1-5 years maturity relative to the United States, depending on availability. 